\title{
Modular pincer-type pyridylidene amide (PYA) ruthenium(II) complexes for efficient transfer hydrogenation catalysis
}

\author{
Philipp Melle, Yanisha Manoharan and Martin Albrecht* \\ Department für Chemie und Biochemie, Universität Bern, Freiestrasse 3, CH-3012 Bern, Switzerland. \\ email: martin.albrecht@dcb.unibe.ch
}

\begin{abstract}
A set of bench-stable ruthenium complexes with new $N, N, N$-tridentate coordinating pincer-type pyridylbis(pyridylideneamide) ligands was synthesized in excellent yields, with the pyridylidene amide in meta or in para position ( $m$-PYA and $p$-PYA, respectively). While complex $\left[\mathrm{Ru}(p-\mathrm{PYA})(\mathrm{MeCN})_{3}\right]^{2+}$ is catalytically silent in transfer hydrogenation, its meta isomer $\left[\mathrm{Ru}(m-\mathrm{PYA})(\mathrm{MeCN})_{3}\right]^{2+}$ shows considerable activity with turnover frequencies at $50 \%$ conversion $\mathrm{TOF}_{50}=100 \mathrm{~h}^{-1}$. Spectroscopic, electrochemical, and crystallographic analyses suggest considerably stronger donor properties of the zwitterionic $m$-PYA ligand compared to the partially $\pi$-acidic $p$-PYA analogue, imparted by valence isomerization. Further catalyst optimization was achieved by exchanging the ancillary $\mathrm{MeCN}$ ligands with imines (4-picoline), amines (ethylenediamine), and phosphines ( $\mathrm{PPh}_{3}, \mathrm{dppm}$, dppe). The most active catalyst was comprised of the $m$ PYA pincer ligand and $\mathrm{PPh}_{3}$, complex $\left[\mathrm{Ru}(m-\mathrm{PYA})\left(\mathrm{PPh}_{3}\right)(\mathrm{MeCN})_{2}\right]^{2+}$, which reached a $\mathrm{TOF}_{50}$ of $430 \mathrm{~h}^{-1}$ under aerobic conditions and up to $4,000 \mathrm{~h}^{-1}$ in the absence of oxygen. The presence of oxygen reversibly deactivates the catalytically active species, which compromises activity, but not longevity of the catalyst. Ligand exchange kinetic studies by NMR spectroscopy indicate that the strong trans effect of the phosphine is critical for high catalyst activity. Diaryl, aryl-alkyl, and dialkyl ketones were hydrogenated with high conversion, and $\alpha, \beta$-unsaturated ketones produced selectively the saturated ketone as the only product due to exclusive $\mathrm{C}=\mathrm{C}$ bond hydrogenation, a distinctly different selectivity from most other transfer hydrogenation catalysts.
\end{abstract}




\section{Introduction}

The pincer ligand motif is typically comprised of a meridional tridentate donor system and has attracted considerable interest as a platform for organometallic and inorganic chemistry. ${ }^{1-10}$ Originally, the pincer platform has been confined to an ECE donor system with a central carbanion and flanking phosphines $(\mathrm{E}=$ $\mathrm{P})^{11}$ or amines $(\mathrm{E}=\mathrm{N}) \cdot{ }^{12,13}$ Complexes with this ECE pincer motif feature a remarkably robust $\mathrm{C}-\mathrm{M}$ bond, which enabled the stabilizaton of a variety of otherwise highly reactive transition states, e.g. for transmetalation, ${ }^{14,15}$ oxidative addition, ${ }^{16}$ or $\mathrm{C}-\mathrm{C}$ bond making and breaking reactions. ${ }^{17-21}$ The pincer platform has been continuously expanded to include a variety of donor combinations. ${ }^{2}$ A particularly versatile and catalytically competent variation includes pincer ligands containing a central pyridyl unit such as PNP and PNN pincer ligands, often referred to as the Milstein system. ${ }^{22-25}$ In these ligands, the central aromatic ring features a lower resonance stabilization energy compared to the benzene ring in aryl-based ECE pincer ligands, which favors deprotonation of the benzylic position and formation of an exocyclic double bond with concomittant pyridine dearomatization. Since this process is reversible, these pincer ligands provide a scaffold for reversible proton storage and release. ${ }^{24,26}$ These ligands are therefore noninnocent and when coordinated to a suitable metal, the complexes offer bifunctionality for efficient catalysis, ${ }^{27-30}$ similar to Noyori's or Shvo's catalyst. ${ }^{31,32}$ This non-innocence of the pincer ligand has been explored by using variations on the theme, including aliphatic backbones ${ }^{33}$ as well as different central heterocycles. $^{34}$

In all these pincer ligands, (de)protonation reversibly changes the ligand donor properties from a neutral imine to a formally anionic amide. We have been intrigued by the possibility to install similar donor flexibility by using resonance flexibility, which does not require the transfer of a proton. Pyridylidene amides (PYAs) ${ }^{35-43}$ offer excellent prospects for such applications, as they exist in two limiting resonance forms: a zwitterionic form with an amide coordination site (A, Scheme 1) and a neutral imine form (B, Scheme 1). Accordingly, the donor properties of this ligand can be modulated by external factors such as the coordinated metal and its spectator ligands and by the polarity of the solvent. ${ }^{44-46}$ The flexibility imparts catalytic activity, and is further modulated upon alteration of the pyridine substitution pattern from paraPYAs (A, B) to meta-PYA scaffolds (C, Scheme 1). ${ }^{47}$ Of note, such meta-PYA ligands cannot be represented by a neutral resonance structure and feature only zwitterionic structures. ${ }^{48}$ Provided resonance structures D-F are also relevant, then these ligands are mesoionic $N$-donor systems, ${ }^{49}$ related to mesoionic $N$-heterocyclic carbenes. ${ }^{50-52}$

The ligand flexibility imparted by these PYA systems offers intriguing opportunities for the stabilization of different metal electronic configurations without the need of chemical transformation of the ligand skeleton. Therefore, we were particularly intrigued by combining the very successful pincer motif and the PYA donor systems to develop catalysts for redox transformations. Here we now present a new member of the pincer family comprised of PYA donors. We demonstrate the electronic control that is exerted by the PYA donors 
on the coordinated ruthenium center, as well as catalytic application in transfer hydrogenation The catalytic activity is optimized by the choice of PYA system as well as the spectator ligands, which allowed turnover numbers to be continuously raised from 100 to $4,000 \mathrm{~h}^{-1}$.

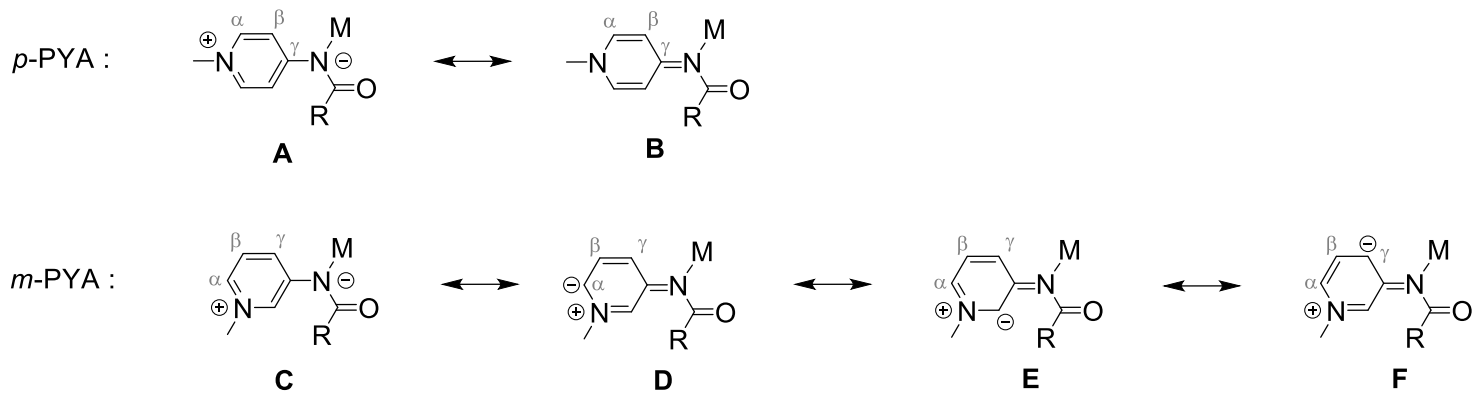

Scheme 1. Limiting resonance structures of para-PYA (top) and meta-PYA ligands.

\section{Results and Discussion}

Synthesis of generic bis-PYA pincer ruthenium complexes. The two PYA pincer ligand precursors L1 and $\mathbf{L 2}$ (Scheme 2) were obtained from the corresponding iodide salts, which were prepared in two straightforward steps according to literature procedures ${ }^{53}$. Anion exchange was performed to avoid iodide ions in the metal complexes, as iodides tend to interfere with redox transformations and was achieved by heating the iodide salts with an excess of $\mathrm{NH}_{4} \mathrm{PF}_{6}$ in a $\mathrm{H}_{2} \mathrm{O} / \mathrm{MeCN}$ mixture (Fig. S1).

The dicationic pincer ruthenium(II) complexes 1 and 2a with para and meta-PYA pincer arms, respectively, were synthesized in excellent yields ( $>90 \%$ ) by an in situ deprotonation/metalation procedure using $\mathrm{Na}_{2} \mathrm{CO}_{3}$ and $\left[\mathrm{RuCl}_{2}(\mathrm{cym})\right]_{2}$ (Scheme 1). This procedure avoids the formation of the neutral free ligand. Complexation was indicated macroscopically by a color change of the reaction mixture from orange to deep red. Complexes 1 and 2a are air- and moisture stable and have been purified by repetitive precipitation. 

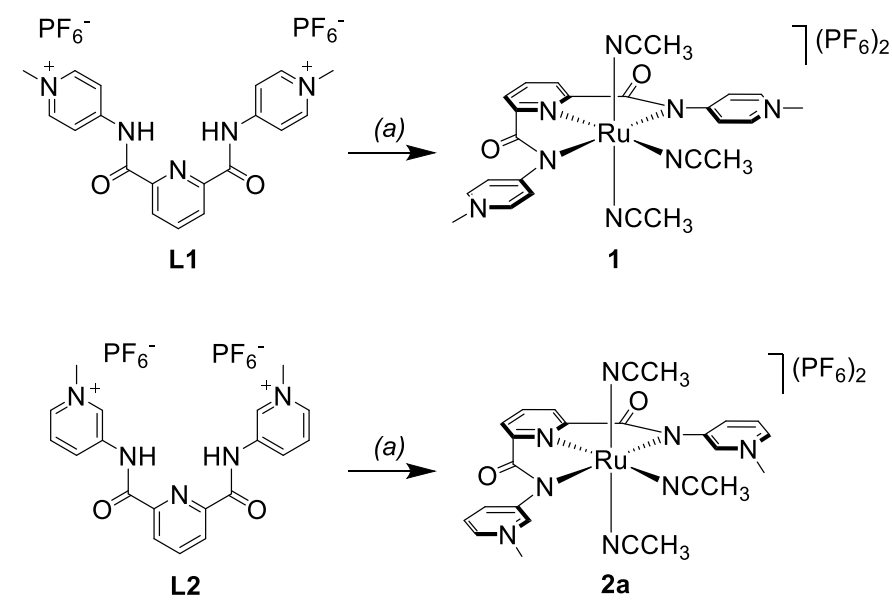

Scheme 2. Synthesis of $\mathrm{Ru}(\mathrm{II})$ PYA pincer complexes 1 and 2a. Reactions and conditions: (a) 0.5 eq. $\left[\mathrm{RuCl}_{2}(\mathrm{cym})\right]_{2}$; 3 eq. $\mathrm{Na}_{2} \mathrm{CO}_{3}$ in $\mathrm{MeCN}$, reflux, $16 \mathrm{~h}$.

Evidence for the formation of the complexes was obtained by ${ }^{1} \mathrm{H}$ NMR spectroscopy, which showed the loss of the amide proton resonances at $\delta_{\mathrm{H}}=11.95$ and 11.67 from $\mathbf{L 1}$ and $\mathbf{L 2}$, respectively. Moreover, the pyridyl proton resonances of the PYA unit shifted markedly upfield upon ruthenation. For example, the two doublets appearing at $\delta_{\mathrm{H}}=8.87$ and 8.49 in $\mathbf{L 1}$ resonate at about $0.5 \mathrm{ppm}$ higher field in the ruthenium complex $1\left(\delta_{\mathrm{H}}=8.52\right.$ and 7.91). Similar shift differences were observed for complex 2a in comparison to the resonances of $\mathbf{L 2}$. The resonances of the coordinated $\mathrm{MeCN}$ ligands appear as two distinct singlets in $2: 1$ integral ratio around $\delta_{\mathrm{H}}=2.3$ and 2.7 for the two axial and the in-plane ligands, respectively, suggesting no significant ligand exchange in DMSO- $d_{6}$. The resonances of the axial MeCN ligands are identical in both complexes, while the equatorial ligand is less shielded in $\mathbf{1}\left(\delta_{\mathrm{H}}=2.76\right)$ than in $\mathbf{2 a}\left(\delta_{\mathrm{H}}=2.65\right)$, indicative of a stronger donation of the m-PYA ligand compared to the para isomer. High resolution MS of the complexes showed the characteristic isotopic signature of ruthenium together with the expected $\mathrm{m} / \mathrm{z}$ signal at $676.0590\left(676.0593\right.$ calculated for $\left.\left[\mathbf{1}-\mathrm{MeCN}_{-} \mathrm{PF}_{6}\right]^{+}\right)$and $\mathrm{m} / \mathrm{z}=717.0859$ (717.0862 calculated for [2$\left.\mathrm{PF}_{6}\right]^{+}$; Fig. S2, S3).

Crystal structure analysis. Single crystal X-ray diffraction analysis of complexes $\mathbf{1}$ and $\mathbf{2 a}$ confirmed the structural assignment (Fig. 1). The molecular structures of complexes $\mathbf{1}$ and 2a both feature a ruthenium center in distorted octahedral geometry with a $N, N, N$-tridentate $m e r$-chelating bis-PYA pincer ligand and three $\mathrm{MeCN}$ spectator ligands. The most severe distortion is entailed by the relatively small bite angle of the bis-PYA pincer ligand, which is identical within esds for complexes $\mathbf{1}$ and $\mathbf{2 a}\left(157.82(14)^{\circ}\right.$ and $157.55(8)^{\circ}$, respectively) and considerably smaller than the ideal $180^{\circ}$. 
a)

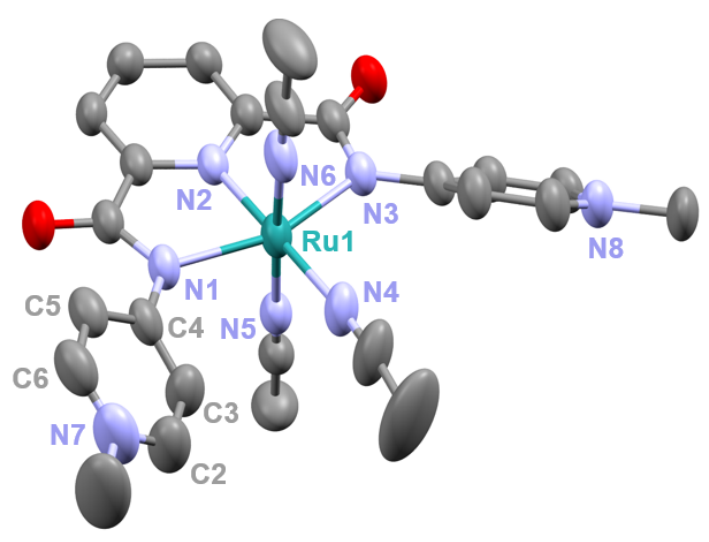

b)

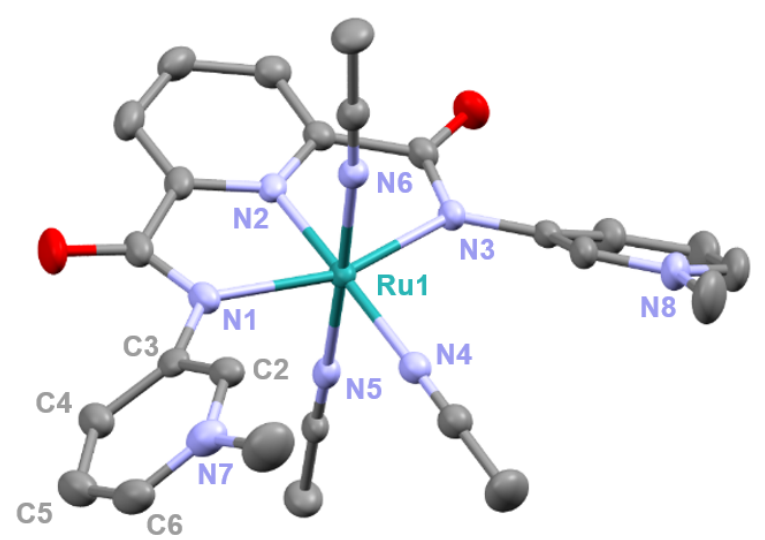

Figure 1. ORTEP representations of the complex cations $\mathbf{1}$ (a) and 2a (b); all ellipsoids at $50 \%$ probability level (hydrogen atoms, non-coordinating $\mathrm{PF}_{6}{ }_{6}$ anions, co-crystallized solvent molecules, and conformational disorder of the methyl-pyridinium groups omitted for clarity).

The metrics around the ruthenium center are almost identical for both complexes. The bond distances between ruthenium and the central pyridyl nitrogen of the PYA pincer ligand $(\mathrm{Ru}-\mathrm{N} 2=1.961(3) \AA$ and 1.9589(19) $\AA$ in $\mathbf{1}$ and 2a, respectively) are substantially shorter compared to the $\mathrm{Ru}-\mathrm{N}_{\mathrm{PYA}}$ bonds (Ru-N1/3 in the 2.102-2.134 $\AA$ range) because of the compressed geometry of the pincer ligands due to the small bite angle (Table 1). In both complexes, the $\mathrm{Ru}-\mathrm{N} 4$ bond to the in-plane $\mathrm{MeCN}$ ligand is slightly longer $(\mathrm{Ru}-$ $\mathrm{N} 4=2.034(3) \AA$ and 2.056(2) $\AA$ in $\mathbf{1}$ and 2a, respectively) than the $\mathrm{Ru}-\mathrm{N}_{\mathrm{MeCN}}$ bond of the axially coordinated MeCN ligands ( $\mathrm{Ru}-\mathrm{N} 5 / 6$ between 2.008(3) and 2.024(2) $\AA$ ). Whereas the $p$-PYA pincer ligand precursor L1 (Fig. S1) reveals a completely planar geometry, similar to the previously reported structure of its iodide analogue,$^{53}$ the PYA heterocycles in the ruthenium complexes are substantially twisted out of the plane of the central pyridine ring by $39.3^{\circ}$ and $40.5^{\circ}$ in complex $\mathbf{1}$ and by $41.8^{\circ}$ and $34.9^{\circ}$ in complex $2 \mathbf{a}$. This large dihedral angle indicates a low $\pi$ contribution to the $\mathrm{N}_{\mathrm{PYA}}-\mathrm{C}_{\mathrm{pyridyl}}$ bond and hence little conjugation between the PYA heterocycle and the metal-bound nitrogen. Accordingly, the amide nitrogen is predominantly anionic and $\pi$-basic as depicted in the zwitterionic limiting resonance structure $\mathbf{A}$ ( $c f$ Scheme $1)$.

A closer look at the bond length alterations within the PYA systems allows for comparison of the mesomeric flexibility of the PYA ligands (Table 1) which is particularly interesting for complex 1 since the $p$-PYA ligand features two strongly diverting limiting resonance structures (zwitterionic aromatic vs. neutral diene, cf Scheme 1). Complex 1 shows distinctly shorter bond distances for $\mathrm{C}_{\alpha}-\mathrm{C}_{\beta}$ compared to $\mathrm{C}_{\beta}-\mathrm{C}_{\gamma}(1.351(7)$ $\AA$ vs. 1.400(7) Å) thus indicating a pronounced diene character (resonance form $\mathbf{A}$ in Scheme 1). In contrast, the ligand $\mathbf{L 1}$ shows an aromatic structure with only $0.026 \AA$ difference between $C_{\alpha}-C_{\beta}$ and $C_{\beta}-C_{\gamma}$. In the $m$-PYA pincer ligand of complex 2a, the bond length alteration is even smaller (less than $0.02 \AA$ ) which is 
in good agreement with a predominantly zwitterionic resonance structure and an aromatic PYA heterocycle. This divergence demonstrates the adaptiveness of the $p$-PYA ligand and agrees with solution NMR data, supporting a formally anionic and stronger $\pi$-basic metal-bound nitrogen of the $m$-PYA unit.

Table 1. Selected bond lengths $(\AA)$ and angles (deg) for ligand $\mathbf{L} \mathbf{1}$ and complexes $\mathbf{1}$ and $\mathbf{2 a}$

\begin{tabular}{lccc}
\hline & $\mathbf{L 1}$ & $\mathbf{1}^{a}$ & $\mathbf{2 a}^{a}$ \\
$\mathrm{Ru} 1-\mathrm{N} 1$ & - & $2.102(3)$ & $2.1064(19)$ \\
$\mathrm{Ru} 1-\mathrm{N} 2$ & - & $1.961(3)$ & $1.9589(19)$ \\
$\mathrm{Ru} 1-\mathrm{N} 3$ & - & $2.134(3)$ & $2.1137(18)$ \\
$\mathrm{Ru} 1-\mathrm{N} 4$ & - & $2.034(4)$ & $2.056(2)$ \\
$\mathrm{Ru} 1-\mathrm{N} 5$ & - & $2.008(4)$ & $2.010(2)$ \\
$\mathrm{Ru} 1-\mathrm{N} 6$ & - & $2.016(4)$ & $2.024(2)$ \\
$\mathrm{N}-\mathrm{C}_{\alpha}{ }^{b}(\mathrm{~N} 7-\mathrm{C} 2, \mathrm{~N} 7-\mathrm{C} 6)$ & $1.341(4)$ & $1.335(8)$ & $1.345(3)$ \\
$\mathrm{C}_{\alpha}-\mathrm{C}_{\beta}{ }^{b}(\mathrm{C} 2-\mathrm{C} 3, \mathrm{C} 5-\mathrm{C} 6)$ & $1.367(4)$ & $1.351(7)$ & $1.374(4)$ \\
$\mathrm{C}_{\beta}-\mathrm{C}_{\gamma}{ }^{b}(\mathrm{C} 3-\mathrm{C} 4, \mathrm{C} 4-\mathrm{C} 5)$ & $1.393(4)$ & $1.400(7)$ & $1.393(4)$ \\
$\mathrm{N} 1-\mathrm{Ru} 1-\mathrm{N} 3$ & - & $157.82(14)$ & $157.55(8)$ \\
$\theta$ PYA-pyr $^{c}$ & 0 & $39.3,40.5$ & $34.9,41.8$ \\
\hline
\end{tabular}

${ }^{a}$ For complexes $\mathbf{1}$ and $\mathbf{2 a}$ the disordered pyridylic ring was not taken into account; ${ }^{b}$ average of two bonds; ${ }^{c}$ dihedral angle $\theta$ between the PYA heterocycles and the $\mathrm{N}-\mathrm{C}=\mathrm{O}$ amide plane.

Preliminary catalytic evaluation. Both complexes were tested as catalysts ( $1 \mathrm{~mol} \%)$ in transfer hydrogenation of benzophenone under standard conditions, ${ }^{54}$ i.e. using $i \mathrm{PrOH}$ as hydrogen source under basic conditions $(10 \mathrm{~mol} \% \mathrm{KOH})$ at reflux temperature and under aerobic conditions. While the $p$-PYA complex 1 was essentially inactive and reached less than 5\% conversion after 6 h, the $m$-PYA complex 2 a showed appreciable catalytic activity with $97 \%$ conversion after 2 h (Fig. 2). 


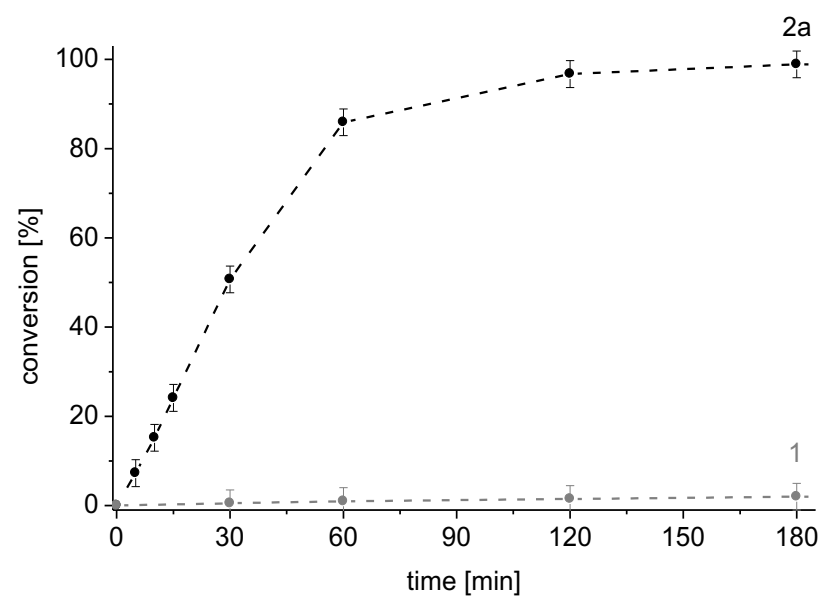

Figure 2. Time-conversion profiles for the transfer hydrogenation of benzophenone in $i \mathrm{PrOH}$ and $\mathrm{KOH}(10 \mathrm{~mol} \%)$ with complex 1 (grey) and complex 2a (black; both at $1 \mathrm{~mol} \%$ ).

To better understand their radically different catalytic behavior, the two complexes were investigated electrochemically using cyclic voltammetry. Both complexes showed two reversible oxidation processes, which were assigned to a consecutive oxidation of the ruthenium center from + II to + III and then to + IV (Fig. 3, Table 2). The $p$-PYA pincer ligand in complex 1 induces higher oxidation potentials $\left(\mathrm{E}_{1 / 2}=+0.78\right.$ $\mathrm{V}$ for $\mathrm{Ru}^{\mathrm{II} / I I}$ and $+1.95 \mathrm{~V}$ for $\mathrm{Ru}^{\mathrm{III} / \mathrm{IV}}$, all potentials $v s$. SSCE) than the $m$-PYA ligand in complex $2\left(\mathrm{E}_{1 / 2}=\right.$ $+0.67 \mathrm{~V}$ and $+1.85 \mathrm{~V}$ ). This $100 \mathrm{mV}$ shift is in agreement with stronger electron donor properties of the $m$ PYA ligand, which can be rationalized by the more pronounced zwitterionic resonance structure contribution, and the low relevance of a $\pi$-acidic imine-type neutral structures ( $c f$ Scheme 1 ). In contrast, the valence isomerization of the $p$-PYA ligand to the imine resonance form in complex 1 reduces the donor properties, and hence this ligand stabilizes lower metal oxidation states, thus entailing higher oxidation potentials. These electrochemical analyses paired with the NMR and solid state studies underline the electronic tunability of bis-PYA pincer ligand without significantly altering of the steric properties.

Table 2. Characteristic electrochemical and photochemical values for complexes $\mathbf{1}$ and $\mathbf{2 a}$

\begin{tabular}{lll}
\hline & $\mathbf{1}$ & 2a \\
$\mathrm{E}_{1 / 2}\left(\mathrm{Ru}^{\mathrm{II} / \mathrm{III}}\right)[\mathrm{V}]^{a}$ & $0.78(77)$ & $0.67(75)$ \\
$\mathrm{E}_{1 / 2}\left(\mathrm{Ru}^{\mathrm{III} / \mathrm{IV}}\right)[\mathrm{V}]^{a}$ & $1.95(148)$ & $1.85(134)$ \\
$\lambda_{\max }(\mathrm{MLCT})[\mathrm{nm}]^{b}$ & $412(8,100) ; 504(4,000)$ & $402(9,100) ; 476(2,900)$ \\
\hline
\end{tabular}

${ }^{a}$ potentials in $\mathrm{MeCN} v s$. SSCE at $100 \mathrm{mV} \cdot \mathrm{s}^{-1}$ scan rate using the $\mathrm{Fc}^{+} / \mathrm{Fc}$ couple as standard; $\mathrm{E}_{1 / 2}=+0.43 \mathrm{~V}$ and $\left(n \mathrm{Bu}_{4} \mathrm{~N}\right) \mathrm{PF}_{6}$ as electrolyte; $\Delta E_{\mathrm{p}}=\left|E_{\mathrm{pc}}-E_{\mathrm{pa}}\right|[\mathrm{mV}]$ in parenthesis. ${ }^{b}$ measured in MeCN; molar extinction coefficient $\varepsilon$ $\left[\mathrm{L} \cdot \mathrm{mol}^{-1} \cdot \mathrm{cm}^{-1}\right]$ in parenthesis. 


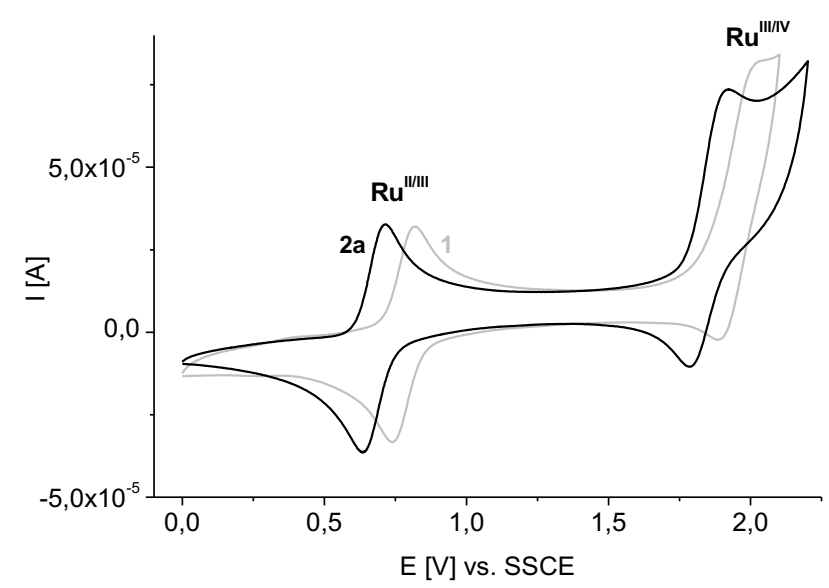

Figure 3. Cyclovoltammetry measurements of complexes $\mathbf{1}$ (grey) and 2a (black) in MeCN (potentials $v s$. SSCE using. the $\mathrm{Fc}^{+} / \mathrm{Fc}$ couple as standard; $\mathrm{E}_{1 / 2}=+0.43 \mathrm{~V} ;\left(n \mathrm{Bu}_{4} \mathrm{~N}\right) \mathrm{PF}_{6}$ as electrolyte, $100 \mathrm{mV} \mathrm{s}^{-1}$ scan rate $)$.

UV-vis absorption spectra show a similar distinction between the effects of the $m$ - and $p$-PYA ligand. The MLCT bands in the visible region of the spectra deriving from metal to ligand $\mathrm{d}-\pi^{*}$ transitions are useful indicators for the electronic impact of the two ligand types. These bands appear at $\lambda_{\max }=412$ and $504 \mathrm{~nm}$ for complex 1 and are hypsochromically shifted to 402 and $476 \mathrm{~nm}$ for complex 2a (Fig. S4). This shift of $\lambda_{\max }$ corroborates a more pronounced $\pi$-acidic diene type structure of the $p$-PYA ligand in complex $\mathbf{1}$, which imparts a higher degree of conjugation and electron delocalization and therefore a smaller energy difference between the HOMO d-orbitals (metal-centered) and the ligand-centered unoccupied $\pi^{*}$ MOs when compared with the electronic configuration in the zwitterionic $m$-PYA ligand.

All analytic data therefore indicate a significant dependence of the metal properties on the PYA substitution pattern and in particular on the position of the $\mathrm{N}-\mathrm{Me}$ group. The $m$-PYA pincer ligand exerts stronger donor properties than the more diene-type $p$-PYA pincer ligand in complex 1, and complex 2a outperforms the $p$ PYA pincer complex 1 by far in transfer hydrogenation catalysis. Therefore, modification of the ancillary ligands in 2a has been envisaged as a methodology to improve catalytic activity and to develop $2^{\text {nd }}$ generation transfer hydrogenation catalysts.

Ancillary ligand modulation of complex 2a. Substitution of the $\mathrm{MeCN}$ spectator ligands in 2a was accomplished upon refluxing an EtOH solution of complex 2a in the presence of extraneous ligands. Based on their distinct steric and electronic impact, a diverse set of ligands was selected, including mono- and bidentate phosphines (diphenylphosphinomethane, dppm; diphenylphosphinoethane dppe; $\mathrm{PPh}_{3}$ ), amines

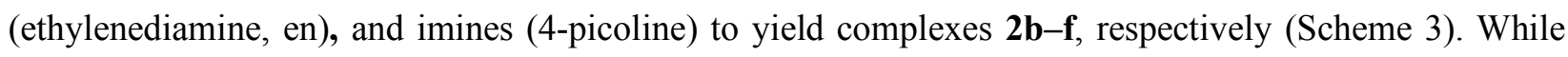
coordination of the bidentate ligands dppm, dppe, and en are unsurprising, it is worth noting that only one 
$\mathrm{PPh}_{3}$ ligand binds to the $\mathrm{Ru}(m$-PYA $)$ unit in axial position, even in the presence of a large excess of phosphine. Coordination of only one phosphine is presumably due to steric constraints imparted by the restricted orientation of the $\mathrm{N}-\mathrm{CH}_{3}$ group of the PYA units. In contrast, picoline coordination is sterically less demanding and substitution from 2a afforded exclusively complex $\mathbf{2} \mathbf{f}$ with two picoline ligands in mutual trans position.

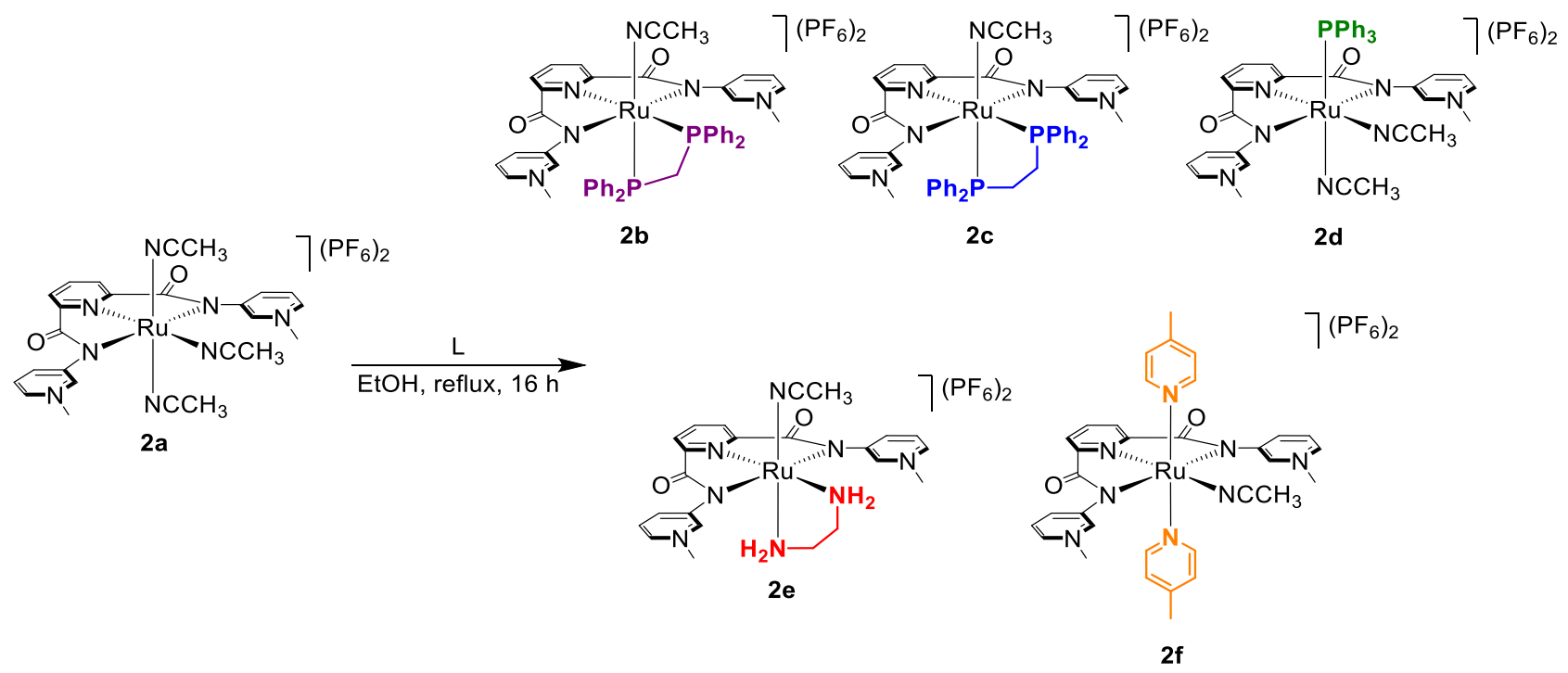

Scheme 3. Synthesis of second-generation ( $m$-PYA) pincer Ru complexes $\mathbf{2 b - f .}$

The formation of complexes 2b-f was confirmed by ${ }^{1} \mathrm{H}$ NMR, ${ }^{13} \mathrm{C}\left\{{ }^{1} \mathrm{H}\right\}$ NMR and ${ }^{31} \mathrm{P}\left\{{ }^{1} \mathrm{H}\right\}$ NMR spectroscopy. The spectra of complexes $\mathbf{2} \mathbf{b}-\mathbf{d}$ feature the expected new proton resonances in the aromatic region integrating to 20 and $15 \mathrm{H}$, respectively. In addition, the singlet due to the $\mathrm{C} 2$-bound hydrogen of the PYA ligand shifts diagnostically upfield upon phosphine coordination from $\delta_{\mathrm{H}}=9.07$ in $2 \mathrm{a}$ to $\delta_{\mathrm{H}} \approx 7.7$ in $\mathbf{2 b}$ and $\mathbf{2 c}$, and less upfield to $\delta_{\mathrm{H}}=8.33$ in the monophosphine complex $\mathbf{2 d}$. The limited steric flexibility of the dppm ligand induces a lower symmetry for complex $\mathbf{2 c}$, as demonstrated by the appearance of two distinct singlets for the $\mathrm{C} 2-\mathrm{H}$ protons of each PYA unit in the ${ }^{1} \mathrm{H}$ NMR spectrum at $\delta_{\mathrm{H}}=7.75$ and 7.73. The cis-coordinating dppm ligand appears as $\mathrm{AB}$ doublets in the ${ }^{31} \mathrm{P}\{\mathrm{H}\}$ NMR spectrum at $\delta_{\mathrm{P}}=0.1$ and -3.2 $\left({ }^{2} J_{\mathrm{PP}}=57.8 \mathrm{~Hz}\right)$ for $\mathbf{2 b}$, and as AX doublet at $\delta_{\mathrm{P}}=66.2$ and $54.3\left({ }^{2} J_{\mathrm{PP}}=13.8 \mathrm{~Hz}\right)$ for $2 \mathbf{c}$. Coordination of only one $\mathrm{PPh}_{3}$ in complex 2d was identified by a singlet at $\delta_{\mathrm{P}}=51.6$ and a 1:2 integral ratio with the highfield $\mathrm{PF}_{6}{ }^{-}$resonance at $\delta_{\mathrm{P}}=-144.6\left(\right.$ septett, $\left.{ }^{1} J_{\mathrm{PF}}=707 \mathrm{~Hz}\right)$. 
Complexes 2e and $\mathbf{2 f}$ with nitrogen-containing ancillary ligands showed the signals expected due to the newly bound en and picoline ligands in the aliphatic and aromatic region, respectively. For example, the picoline resonances of complex $2 \mathbf{f}$ appear as two characteristic doublets $\left(\delta_{\mathrm{H}}=7.69\right.$ and $\left.7.06,{ }^{3} J_{\mathrm{HH}}=6.6 \mathrm{~Hz}\right)$ and integrated for two symmetry-related and hence mutually trans coordinated ligands. Interestingly, the $\mathrm{C} 2-\mathrm{H}$ proton resonance is less shifted upon en coordination $\left(\delta_{\mathrm{H}}=8.48\right)$ than in the phosphine complexes, and it is unchanged in the picoline complex $2 \mathbf{f}$ at $\left(\delta_{\mathrm{H}}=9.08, \operatorname{cf} 9.07\right.$ for 2a). The $\mathrm{C} 2-\mathrm{H}$ proton resonance of the $m$-PYA unit therefore is a sensitive probe for the stereoelectronic impact of the ancillary ligands.

Modification of the ancillary ligands also had a marked influence on the lability of the residual MeCN ligands. While NMR spectra in deuterated MeCN or DMSO did not indicate any substitution of this ligand in complexes with $\mathrm{N}$-donor ligands (2a, 2e, and $\mathbf{2 f}$ ), phosphine coordination in complexes $\mathbf{2} \mathbf{b}-\mathbf{d}$ induced rapid ligand exchange in both solvents and no coordinated $\mathrm{MeCN}$ was observed in the ${ }^{1} \mathrm{H}$ NMR spectrum of the dppx complexes $\mathbf{2 b}$ and $\mathbf{2 c}$. For complex $\mathbf{2 d}$ only one resonance for coordinated $\mathrm{MeCN}$ was observed $\left(\delta_{\mathrm{H}}=2.98\right.$ in $\mathrm{DMSO}-d_{6}$ and and 2.67 in $\mathrm{MeCN}-d_{3}$, respectively), which decreased in a zero-order reaction and completely disappeared after $24 \mathrm{~h}$ (Fig. S8, S9). In non-coordinating $\mathrm{CD}_{2} \mathrm{Cl}_{2}$ both coordinated $\mathrm{MeCN}$ ligands were observed and resonante at $\delta_{\mathrm{H}}=2.26$ and 2.54 (Fig. S10).

1D NOESY measurements of $\mathbf{2} \mathbf{d}$ in $\mathrm{CD}_{2} \mathrm{Cl}_{2}$ and $\mathrm{MeCN}-d_{3}$ were carried out to unambiguously assign the position of the MeCN ligands and to investigate the rotation dynamics of the PYA units in solution (Fig. $\mathrm{S} 11-\mathrm{S} 15)$. Upon saturation of the $\mathrm{MeCN}$ proton resonance at $\delta_{\mathrm{H}}=2.54$ in $\mathrm{CD}_{2} \mathrm{Cl}_{2}$ solution, spin-spin coupling to the $\mathrm{N}-\mathrm{CH}_{3}$ protons of the PYA unit $\left(\delta_{\mathrm{H}}=4.31\right)$ and to the $\mathrm{PPh}_{3}$ protons $\left(\delta_{\mathrm{H}}=6.8-6.9\right.$ and $7.0-$ 7.1) was observed, suggesting an equatorial position of this MeCN ligand and a cis relationship with $\mathrm{PPh}_{3}$. In contrast, saturation of the $\mathrm{MeCN}$ resonance at $\delta_{\mathrm{H}}=2.26$ did not show any interaction with the $\mathrm{PPh}_{3}$ protons nor the $\mathrm{N}-\mathrm{CH}_{3}$ group, which is in agreement with an axial position with respect to the pincer ligand plane (viz. trans to $\mathrm{PPh}_{3}$ ). In $\mathrm{MeCN}-d_{3}$, one $\mathrm{MeCN}$ ligand is rapidly exchanging and only one $\mathrm{NCCH}_{3}$ resonance was observed (vide supra). Saturation of this resonance $\left(\delta_{\mathrm{H}}=2.67\right)$ revealed an NOE with the $\mathrm{PPh}_{3}$ protons, indicating that the axial $\mathrm{MeCN}$ ligand is significantly more labile, in agreement with the higher trans effect of $\mathrm{PPh}_{3} v s$ the pyridyl donor site ${ }^{55}$ of the pincer ligand.

Irrespective of the solvent $\left(\mathrm{CD}_{2} \mathrm{Cl}_{2}\right.$ or $\left.\mathrm{MeCN}-d_{3}\right)$, NOEs were also observed between the equatorial $\mathrm{MeCN}$ proton resonances and three of the four protons of the pyridylidene heterocycle $\left(\mathrm{H}^{2}, \mathrm{H}^{4}\right.$, and $\left.\mathrm{H}^{5}\right)$. These interactions indicate substantial wagging of the PYA unit about the exocyclic $\mathrm{C}-\mathrm{N}_{\text {PYA }}$ bond and suggest single bond character of this bond. Such a conclusion is corroborating the preponderance of the zwitterionic PYA form ( $\mathbf{C}$ in Scheme 1$)$ and provides another indication for a formally anionic and $\pi$-basic PYA nitrogen donor site in complex $\mathbf{2 a}$. 
Interestingly, the different degrees of lability of the MeCN ligand are also reflected in the HR-MS data of complexes $\mathbf{2 b}-\mathbf{f}$. The phosphine complexes $\mathbf{2 b}-\mathbf{d}$ all show a $\mathrm{M}^{+}$signal resulting from dissociation of a $\mathrm{PF}_{6}{ }^{-}$ anion and all $\mathrm{MeCN}$ ligands $\left(\mathrm{m} / \mathrm{z}=978.1259\right.$ for $\left[\mathbf{2 b}-\mathrm{MeCN}_{-} \mathrm{PF}_{6}\right]^{+}, 992.1430$ for $\left[\mathbf{2 c}-\mathrm{MeCN}-\mathrm{PF}_{6}\right]^{+}$, and 856.0985 for $\left.\left[\mathbf{2 d}-2 \mathrm{MeCN}_{-} \mathrm{PF}_{6}\right]^{+}\right)$in excellent agreement with the calculated values $(978.1259,992.1415$, and 856.0973, respectively). In contrast, the $\mathrm{N}$-donor complexes ionized only via loss of the $\mathrm{PF}_{6}{ }^{-}$anion, and the mother ion included the coordinated $\mathrm{MeCN}$ ligand $\left(\mathrm{m} / \mathrm{z}=695.1032\right.$ for $[\mathbf{2} \mathbf{e}-\mathrm{PF}]^{+}$and 821.1528 for $[\mathbf{2 f}-$ $\left.\mathrm{PF}_{6}\right]^{+}$.

Crystallographic analysis. The structures of complexes $\mathbf{2 b - d}$ and $\mathbf{2 f}$ were unequivocally confirmed by single crystal X-ray diffraction analysis. All complexes show a distorted octahedral ruthenium center with the $m$-PYA pincer ligand in a meridional coordination mode (Fig. 4). The bite angle of the pincer ligand $\mathrm{N} 1-\mathrm{Ru}-\mathrm{N} 3$ decreases from $157.6^{\circ}$ in the solvento complex $\mathbf{2 a}$ to $155.8^{\circ}$ in $\mathbf{2 d}$ with one $\mathrm{PPh}_{3}$ ligand and even further to $152.6^{\circ}$ and $152.9^{\circ}$ in the bidentate dppx complexes $\mathbf{2 b}$ and $\mathbf{2 c}$ (Table 2). The phenyl rings of the dppx ligands and the PYA heterocycle are oriented in a parallel manner, indicative of $\pi$-stacking interactions. These interactions lead to large twist of the PYA heterocycle out of the pyridylamide plane with dihedral angles between $61-82^{\circ}$ in complexes $\mathbf{2 b}$ and $\mathbf{2 c}$ compared to less than $42^{\circ}$ in complexes $2 \mathbf{a}$, 2d and 2f. Another distinctive feature is the expected higher trans influence of the phosphine ligand compared to pyridine in these complexes as demonstrated by the lengthening $\mathrm{Ru}-\mathrm{N}_{\mathrm{pyr}}$ and $\mathrm{Ru}-\mathrm{N}_{\mathrm{MeCN}}$ bonds. This higher trans influence correlates here also with a higher trans effect, as noted for the fast substitution of the MeCN ligand trans to a phosphine in complexes $\mathbf{2} \mathbf{b}-\mathbf{d}$. 
a)

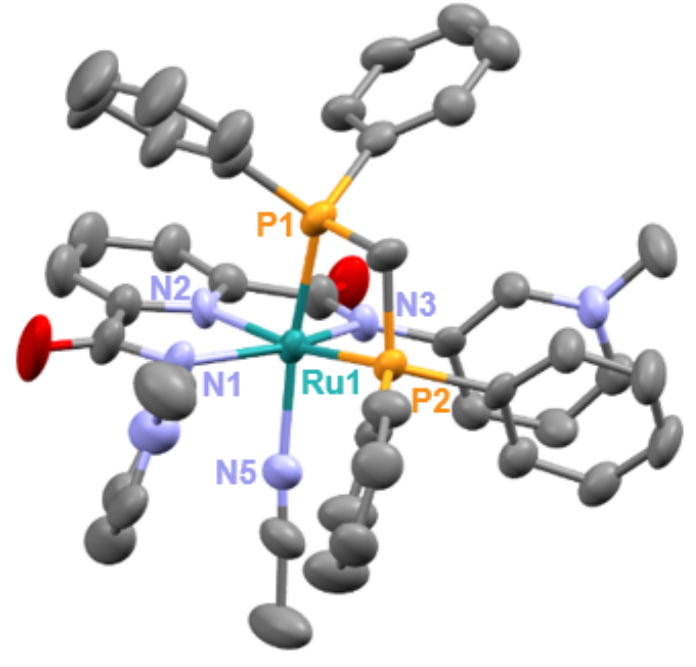

c)

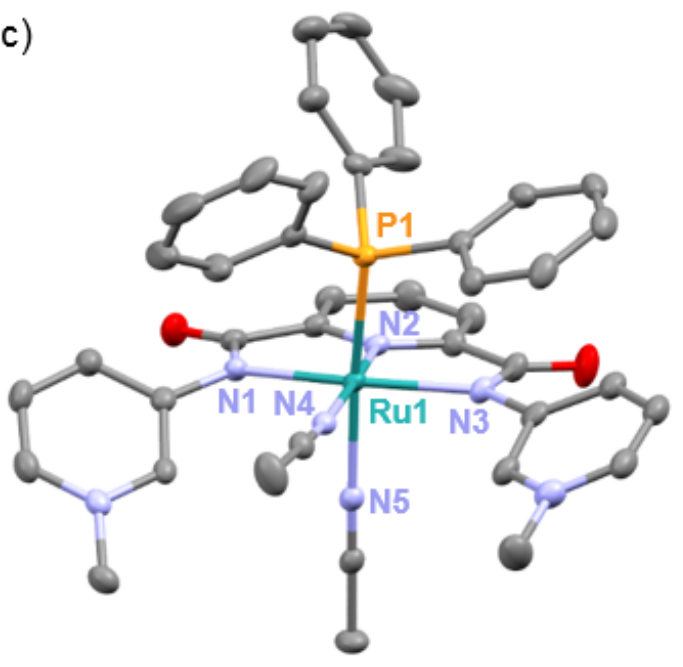

b)

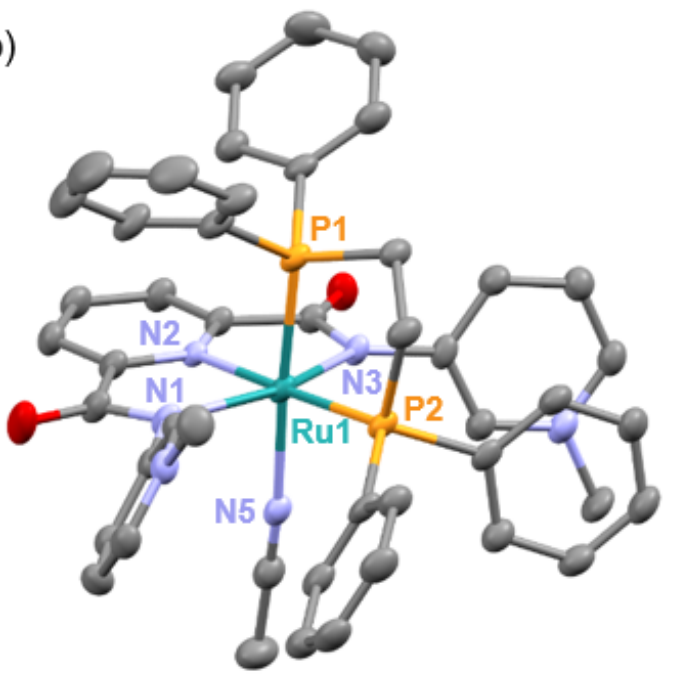

d)

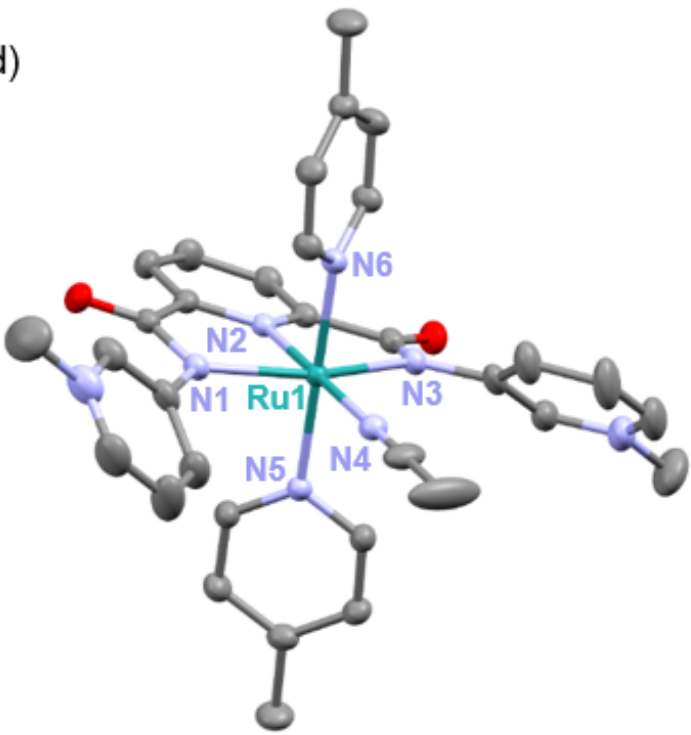

Figure 4. ORTEP representations of the complex cations of $\mathbf{2 b}$ (a), $\mathbf{2 c}$ (b), $\mathbf{2 d}(\mathrm{c})$ and $\mathbf{2 f}(\mathrm{d})$; all ellipsoids at $50 \%$ probability, $\mathrm{H}$ atoms, non-coordinating $\mathrm{PF}_{6}{ }^{-}$anions, co-crystallized solvent molecules, and conformational disorder of methyl-pyridinium rings omitted for clarity.

Table 3. Selected bond lengths ( $\AA$ ) and angles (deg) for complexes $\mathbf{2 a - d}$ and $\mathbf{2 f}$

\begin{tabular}{llllll}
\hline & $\mathbf{2 a}\left(\mathrm{L}_{\mathrm{ax}}=\mathrm{N} 5\right)$ & $\mathbf{2 b}\left(\mathrm{L}_{\mathrm{ax}}=\mathrm{P} 1\right)$ & $\mathbf{2 c}\left(\mathrm{L}_{\mathrm{ax}}=\mathrm{P} 1\right)$ & $\mathbf{2 d}\left(\mathrm{L}_{\mathrm{ax}}=\mathrm{P} 1\right)$ & $\mathbf{2 f}\left(\mathrm{L}_{\mathrm{ax}}=\mathrm{N} 5\right)$ \\
$\mathrm{Ru}-\mathrm{N} 1$ & $2.1064(19)$ & $2.114(5)$ & $2.161(3)$ & $2.147(2)$ & $2.1208(18)$ \\
$\mathrm{Ru}-\mathrm{N} 2$ & $1.9589(19)$ & $2.034(5)$ & $2.047(3)$ & $1.977(2)$ & $1.953(2)$ \\
$\mathrm{Ru}-\mathrm{N} 3$ & $2.1137(18)$ & $2.134(4)$ & $2.146(3)$ & $2.136(2)$ & $2.1208(18)$ \\
$\mathrm{Ru}-\mathrm{N} 4$ or Ru-P2 & $2.056(2)$ & $2.2951(15)$ & $2.3209(10)$ & $2.050(2)$ & $2.055(3)$ \\
$\mathrm{Ru}-\mathrm{N} 5$ & $2.010(2)$ & $2.102(5)$ & $2.118(3)$ & $2.096(2)$ & $2.0910(18)$
\end{tabular}




\begin{tabular}{llllll}
$\mathrm{Ru}-\mathrm{L}_{\mathrm{ax}}$ & $2.024(2)$ & $2.2642(16)$ & $2.2802(11)$ & $2.3271(6)$ & $2.0910(18)$ \\
$\mathrm{N} 1-\mathrm{Ru}-\mathrm{N} 3$ & $157.55(8)$ & $152.6(2)$ & $152.85(12)$ & $155.79(8)$ & $157.06(10)$ \\
$\theta$ PYA-pyr $^{a}$ & $34.9,41.8$ & $76.9,79.3$ & $61.7,81.9$ & $31.6,40.2$ & $41.3,41.3$ \\
\hline
\end{tabular}

${ }^{a}$ dihedral angle $\theta$ between the PYA heterocycles and the pyridylamide plane.

Electrochemical and UV-vis spectroscopic analysis. Electrochemical measurements and spectroscopic data suggest a strong influence of the different spectator ligands on the electronic properties of the $\mathrm{Ru}(\mathrm{II})$ metal center. Cyclic voltammetry in $\mathrm{MeCN}$ shows for all complexes a reversible oxidation in the +0.2 to $+1.0 \mathrm{~V}$ range which was attributed to a metal-centered $\mathrm{Ru}^{\mathrm{II} / I I}$ redox process. ${ }^{56}$

When comparing the half-wave potentials (Fig. 5, Table S1) a trend emerges that correlates with the donor properties of the ancillary ligand. The oxidation potentials increase in the sequence $2 \mathbf{e}(0.26 \mathrm{~V})<\mathbf{2 f}(0.46$ $\mathrm{V})<\mathbf{2} \mathbf{a}(0.67 \mathrm{~V})<\mathbf{2 d}(0.79 \mathrm{~V})<\mathbf{2} \mathbf{c}(0.86 \mathrm{~V}) \approx \mathbf{2} \mathbf{b}(0.88 \mathrm{~V}$; all potentials $v s$ SSCE $)$, in agreement with the hardness of the ligand setting, which decreases in the order of en (2e) $>$ pyr (2f) $>\operatorname{RCN}(\mathbf{2 a})>P_{3}(\mathbf{2 d})$. Exchange of another MeCN ligand by a second phosphine (2b, 2cc) further reduces the electron density at the metal center and hence increases the potential needed to reach the oxidized $\mathrm{Ru}^{\mathrm{III}}$ state. Hence, the ancillary ligands allow the electronic properties of the ruthenium center to be tailored over a substantial potential range.

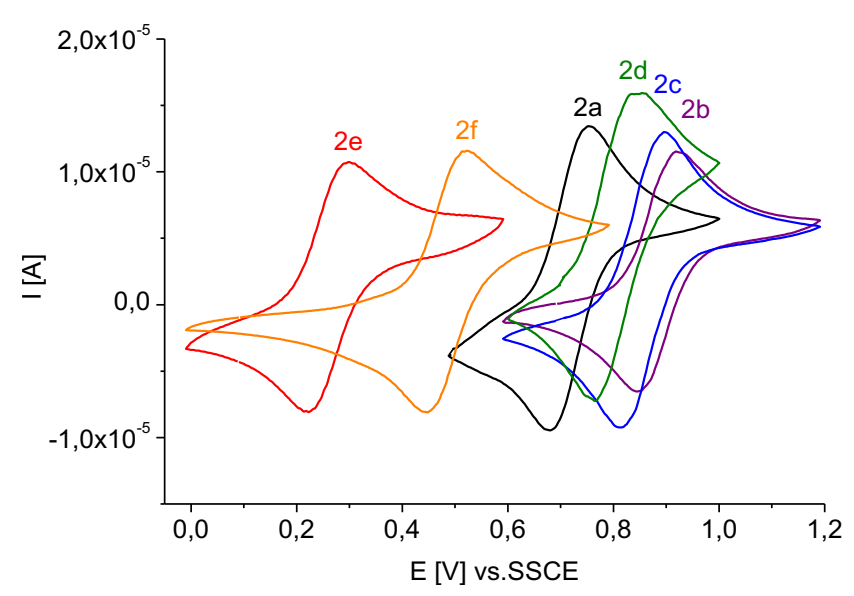

Figure 5. Cyclovoltammetry measurements of the $m$-PYA Ru(II) complex variations 2 a (black, $\mathrm{L}=\mathrm{MeCN}$ ), 2 b (purple, $\mathrm{L}=\mathrm{dppm}$ ), 2c (blue, $\mathrm{L}=$ dppe), $\mathbf{2 d}$ (green, $\mathrm{L}=\mathrm{PPh}_{3}$ ), $\mathbf{2 e}($ red, $\mathrm{L}=\mathrm{en}$ ) and $\mathbf{2 f}$ (orange, $\mathrm{L}=4$-picoline) in $\mathrm{MeCN}$ showing the reversible redox processes for the $\mathrm{Ru}^{\mathrm{II} / \mathrm{III}}$ transition (potentials $v s$. SSCE using. the $\mathrm{Fc}^{+} / \mathrm{Fc}$ couple as standard; $E_{1 / 2}=+0.43 \mathrm{~V} ; n \mathrm{Bu}_{4} \mathrm{NPF}_{6}$ as supporting electrolyte, $100 \mathrm{mV} \mathrm{s}^{-1}$ scan rate).

Photospectroscopic measurements of the complexes show an absorption in the 350-450 nm range that was assigned to a $d-\pi^{*}$ MLCT band (Fig. S5). The absorption maximum $\lambda_{\max }$ of this band is strongly dependent 
on the ancillary ligand and shifts to higher energy as the ligand hardness is reduced following the sequence $\mathbf{2 e}(456 \mathrm{~nm})>\mathbf{2 f}(437 \mathrm{~nm})>\mathbf{2 a}(402 \mathrm{~nm})>\mathbf{2 d}(390 \mathrm{~nm})>\mathbf{2 b}(367 \mathrm{~nm}) \approx \mathbf{2 c}(360 \mathrm{~nm})$. This sequence is identical to the order of redox potentials established by electrochemical measurements and hence supports the notion that the electronic properties of these $m$-PYA pincer ruthenium complexes can be tailored over a broad range. Interestingly, a plot of the absorption maxima $\left(\lambda_{\max }\right) v s$ the redox potentials $\left(E_{1 / 2}\right)$ is linear (Fig. 6), indicative of a direct correlation. Since the $\mathrm{Ru}^{\mathrm{II} / \mathrm{III}}$ redox potentials are predominantly affected by the metal $4 \mathrm{~d}$ orbital energy of the HOMO, the linear correlation with $\lambda_{\max }$ implies that the energy of the LUMO remains constant. It therefore follows that for all investigated complexes $\mathbf{2 a}-\mathbf{f}$, the LUMO is centered on the $m$-PYA pincer ligand. Considering the $\pi$-basic nature of the amide donor sites of the PYA pincer ligand, these data suggest the LUMO to be largely localized on the central pyridyl ring. Hence this pincer ligand is behaving as a $\pi$ acid, qualitatively similar to terpyridine.

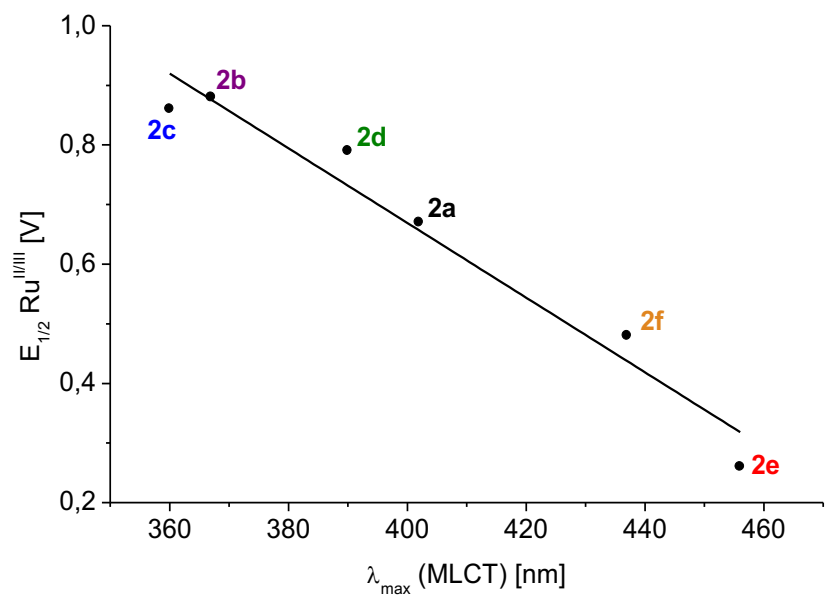

Figure 6. Linear correlation of the $\mathrm{Ru}^{\mathrm{II} / I I I}$ redox potentials $E_{1 / 2}$ with the maximum absorption $\lambda_{\max }$ of the MLCT process for the $m$-PYA pincer ruthenium complexes $2 \mathbf{a}-\mathbf{f}\left(\mathrm{R}^{2}=0.95\right)$.

Catalytic transfer hydrogenation activity of complexes $\mathbf{2 a}-\mathbf{f}$. The $2^{\text {nd }}$ generation $m$-PYA pincer ruthenium(II) complexes $\mathbf{2 b}-\mathbf{f}$ were tested as catalyst precursors for the transfer hydrogenation of benzophenone in $i \mathrm{PrOH}$ under basic conditions and compared to 2a. At $1 \mathrm{~mol} \%$ ruthenium loading, the complexes with ancillary phosphine ligands $\mathbf{2} \mathbf{b}-\mathbf{d}$ displayed the best performance of the series and reached turnover frequencies at $50 \%$ conversion $\left(\mathrm{TOF}_{50}\right)$ up to $430 \mathrm{~h}^{-1}$ (Fig. 7, Table 4, entries 2-4), which is a threefold increase compared to complex 2a with $\mathrm{MeCN}$ ancillary ligands $\left(\mathrm{TOF}_{50}=100 \mathrm{~h}^{-1}\right.$; entry 1). Complexes $2 \mathbf{e}$ and $\mathbf{2 f}$ with en and pyridine ancillary ligands, respectively, were considerably less active (entries 8, 9). While complex $2 \mathrm{f}$ reached almost $70 \%$ conversion after $2 \mathrm{~h}\left(\mathrm{TOF}_{50}=40 \mathrm{~h}^{-1}\right)$, the en-containing complex 2e was essentially inactive and reached a modest $20 \%$ conversion after $2 \mathrm{~h}$. This substantial variation of catalytic activity in complexes $\mathbf{2 a}-\mathbf{f}$ demonstrates the tunability of the $m$-PYA pincer ruthenium unit. 


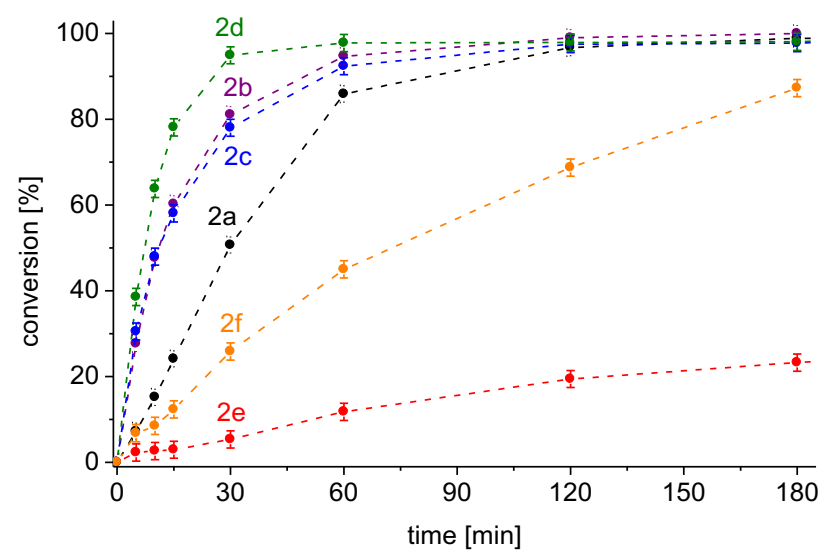

Figure 7. Time-conversion profile for $m$-PYA ruthenium complexes with variable ancillary ligands in the transfer hydrogenation of benzophenone: 2a (black), $\mathbf{2 b}$ (purple), $\mathbf{2 c}$ (blue), $\mathbf{2 d}$ (green), $\mathbf{2 e}$ (red) and $\mathbf{2 f}$ (orange).

Table 4. Catalytic activity of complexes $\mathbf{1}$ and $\mathbf{2 a}-\mathbf{f}$ in transfer hydrogenation of benzophenone ${ }^{\text {a }}$

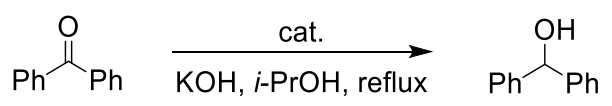

\begin{tabular}{lllllc}
\hline entry & cat. & \multicolumn{3}{c}{ yield (\%) } & TOF $_{50}\left(\mathrm{~h}^{-1}\right)$ \\
\cline { 3 - 5 } & & $0.25 \mathrm{~h}$ & $0.5 \mathrm{~h}$ & $2 \mathrm{~h}$ & \\
2 & $\mathbf{2 a}$ & 24 & 51 & 97 & 100 \\
3 & $\mathbf{2 b}$ & 60 & 81 & 99 & 300 \\
4 & $\mathbf{2 c}$ & 58 & 78 & 98 & 300 \\
5 & $\mathbf{2 d}$ & 78 & 95 & 98 & 430 \\
$6^{\mathrm{c}}$ & $\mathbf{2 d}$ & 18 & 26 & 44 & 150 \\
$7^{\mathrm{d}}$ & $\mathbf{2 d}$ & $<2$ & $<2$ & $<2$ & - \\
8 & $\mathbf{2 e}$ & 3 & 5 & 20 & - \\
9 & $\mathbf{2 f}$ & 12 & 26 & 69 & 40 \\
\hline
\end{tabular}

${ }^{a}$ General reaction conditions: benzophenone ( $\left.1 \mathrm{mmol}\right), \mathrm{KOH}(0.1 \mathrm{mmol}, 10 \mathrm{~mol} \%),[\mathrm{Ru}](0.01 \mathrm{mmol}, 1 \mathrm{~mol} \%)$, $i \mathrm{PrOH}(5 \mathrm{~mL})$, reflux temperature. ${ }^{\mathrm{b}}$ determined by GC using hexadecane as internal standard and averaged over at least two runs, conversions correspond with yields. ${ }^{\mathrm{c}}[\mathrm{Ru}](0.001 \mathrm{mmol}, 0.1 \mathrm{~mol} \%) .{ }^{\mathrm{d}}$ Without base

When the most active catalyst $\mathbf{2 d}$ was evaluated at lower catalyst loadings of $0.1 \mathrm{~mol} \%$, catalytic activity was preserved with a $\mathrm{TOF}_{50 \%}$ of $150 \mathrm{~h}^{-1}$ (entry 6 ), though considerably longer reaction times were required to reach high conversion ( $87 \%$ after $24 \mathrm{~h}$, corresponding to 870 turnovers). The presence of a base is essential, as under base-free conditions no substrate was converted (entry 7).

While the enhanced catalytic activity of the $m$-PYA pincer complex in comparison to the $p$-PYA analogue was attributed to the stronger donor properties of the mesoionic PYA ligand sites in complex 2, such arguments based on electron donor ability fall short to rationalize the observed catalytic activity trend for 
2a-f. The complexes with the highest redox potential, i.e. the phosphine complexes with the least electrondonating ligand set, show the highest catalytic activity. In fact, the ligand donor properties correlate inversely with the catalytic activity. A more plausible rationale for the high catalytic activity of complexes 2b-d therefore invokes the high trans effect of the phosphine ligand, which labilizes in particular the $\mathrm{MeCN}$ ligand trans to the phosphine ( $c f$ NMR studies above). According to such a model, substrate coordination and presumably also product release is facilitated in these complexes. Steric congestion imparted by the equatorial phosphine in the diphosphine complexes $\mathbf{2 b}$ and $\mathbf{2 c}$ may account for the slightly lower activity of these complexes when compared to the monophosphine complex $\mathbf{2 d}$.

Catalytic transfer hydrogenation studies with $2 \mathrm{~d}$ as the most active complex. Based on its high activity, complex 2d was used to investigate catalyst longevity and a brief substrate scope. The robustness of the catalytically active species was probed by increasing the substrate/catalyst (S/C) ratio. At a 1,000:1 S/C ratio, the reaction is considerably slower and $24 \mathrm{~h}$ rather than $30 \mathrm{~min}$ are required to reach synthetically useful conversions. Lowering the catalyst concentration from $1 \mathrm{mM}$ to $0.1 \mathrm{mM}$ (cf entry 6 in Table 3 ) had the same effect as increasing the substrate concentration from $0.1 \mathrm{M}$ to $1 \mathrm{M}$, suggesting that the intrinsic stability of the catalytic species is limiting the longevity and not potential impurities of the solvent or aerobic oxidative catalyst degradation. In an attempt to preserve the high turnover frequency observed when applying a 100:1 S/C ratio, a further experiment was carried out in which 100 equiv. benzophenone were added consecutively each $20 \mathrm{~min}$. After 10 additions, the same 1,000:1 S/C ratio was reached. A $20 \mathrm{~min}$ interval was selected because after this time, the 100:1 S/C run shows high but not full conversion ( $c f$ entry 5, Table 3). This situation ensures that the catalyst is still active.

The conversion profile of this run with stepwise addition of substrate reveals a gradual decrease of catalytic activity as shown by the reduction of turnover numbers (TONs) within each 20 min segment, from 78 in the first segment to a modest 10 in the last segment (Fig. 8). Interestingly however, after $8 \mathrm{~h}$, the conversion is essentially identical to runs which started directly at a 1,000:1 S/C ratio (TONs of $750 \pm 50$ ). This result implies that catalytic activity resumes after the additions are complete (i.e. after $200 \mathrm{~min}$ ) and that the repeated sampling and substrate addition is inhibiting catalytic turnover. Inhibition has been attributed to a reversible deactivation of the catalytically active species by oxygen. Such deactivation is promoted by the repetitive opening of the reaction vessel for sampling and is reversed by solution degassing through reflux. Support for such a conclusion was obtained from a run in which only substrate was added but no samples were taken to determine conversion. After $210 \mathrm{~min}$, this run reached much higher conversion than when sampling after each substrate addition (520 vs $420 \mathrm{TON}$, compare to $710 \mathrm{TON}$ of a sample starting at 1,000:1 ratio without any sampling or substrate addition). However, final conversions are identical with previous runs, which is in agreement with a reversible deactivation of the catalytic species. Moreover, a catalytic run 
at 1,000:1 ratio under strict exclusion of air featured the highest catalytic activity, reaching a $\mathrm{TOF}_{50}$ of 4,000 $\mathrm{h}^{-1}$ (7.5 min for $50 \%$ conversion), almost full conversion after $30 \mathrm{~min}$, and a final TON of 990 . These experiments provide strong support for reversible catalyst inhibition by oxygen, in agreement with the formation of a sensitive hydride species with sufficiently long life time. ${ }^{57}$ Moreover, the regeneration of the active species under reflux conditions indicates a catalytic species that is molecularly well-defined and homogeneously operating.

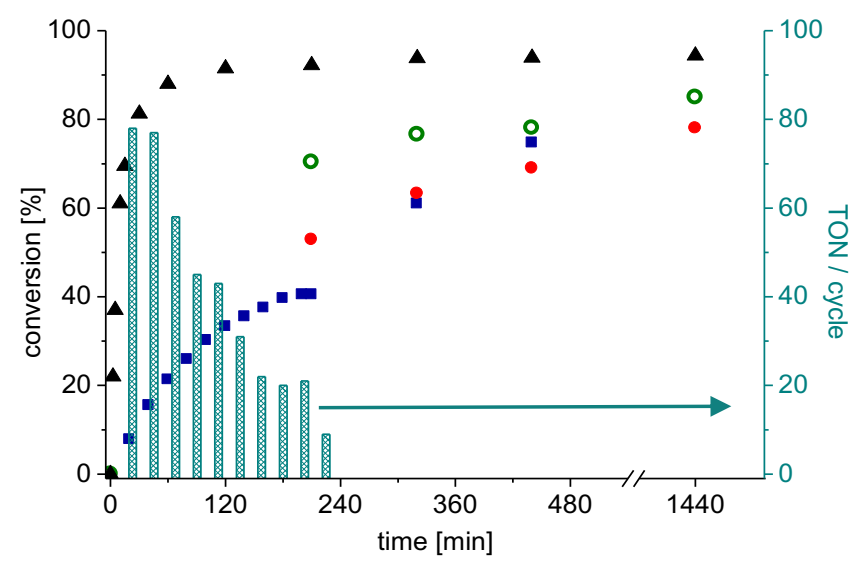

Figure 8. Conversion and TON profiles for the transfer hydrogenation of benzophenone with complex $\mathbf{2 d}$ in $i \mathrm{PrOH}$ under different conditions: - stepwise addition of 10x 100 equiv. substrate every 20 min (sampling every $20 \mathrm{~min}$ ); pillars show the TON for each of those 10 cycles; • stepwise addition of 100 equiv. substrate every 20 min (with no sampling before $210 \mathrm{~min}$ ); o S/C 1000:1 from onset under aerobic conditions; $\boldsymbol{\Delta}$ S/C 1000:1 from onset under $\mathrm{N}_{2}$ atmosphere; conversions are plotted based on the final 1000:1 S/C ratio.

A preliminary evaluation of the substrate scope of complex 2d involved diaryl, aryl-alkyl, and dialkyl ketones, which were hydrogenated with high conversion, including open chain and cyclic aliphatic ketones (see Fig. S16, S17 for time-conversion profiles). Transfer hydrogenation of (substituted) acetophenones under aerobic conditions proceeded at rates that are comparable to those observed for the reduction of benzophenone (entries 1-8). No direct electronic effect was observed and electron withdrawing (e.g. $-\mathrm{CF}_{3}$, entry 6) as well as electron-donating groups (-OMe, entry 4) were converted at similar rates, though slightly slower in comparison to unsubstituted acetophenone (entry 2). Nitrogen-containing substituents were incompatible with the catalyst and both nitro as well as amine groups inhibited transfer hydrogenation significantly, presumably due to amine coordination to the active site. Remarkably, sterically shielded 2methylacetophenone was hydrogenated faster than the unshielded parent substrate and $>90 \%$ conversion was achieved already after 15 min (entry 8). Steric shielding of the alkyl side of acetophenone led to decreased catalytic rates and isobutyrophenone was hydrogenated only to $46 \%$ within the same reaction period (entry 9). Cyclohexanone as a representative cyclic aliphatic ketone was converted very rapidly and essentially complete conversion was noted after $15 \min$ (entry 10). In contrast, open chain aliphatic ketones 
such as 2-octanone and 4-phenyl-2-butanone react slightly slower than acetophenone and up to $2 \mathrm{~h}$ are required to reach maximum conversion (entries 11,12). 
Table 5. Substrate scope of complex $\mathbf{2 d}$ in catalytic transfer hydrogenation ${ }^{a}$

\begin{tabular}{|c|c|c|c|c|c|}
\hline \multirow{3}{*}{ entry } & \multirow{3}{*}{ substrate } & $\overline{\mathrm{KOH}}$, & $\overrightarrow{\text { eflux }}$ & $\mathrm{R}_{\mathrm{R}^{\prime}}^{\stackrel{\mathrm{OH}}{\lambda}}$ & \multirow{3}{*}{$\mathrm{TOF}_{50}\left(\mathrm{~h}^{-1}\right)$} \\
\hline & & \multicolumn{3}{|c|}{ yield $(\%)^{b}$} & \\
\hline & & $0.25 \mathrm{~h}$ & $0.5 \mathrm{~h}$ & $2 \mathrm{~h}$ & \\
\hline 1 & & 78 & 95 & 98 & 430 \\
\hline 2 & & 82 & 98 & $>99$ & 350 \\
\hline 3 & & 26 & 36 & 49 & 20 \\
\hline 4 & & 73 & 85 & 90 & 450 \\
\hline 5 & & 71 & 95 & $>99$ & 290 \\
\hline 6 & & 65 & 88 & $>99$ & 300 \\
\hline 7 & & $<2$ & $<2$ & $<2$ & - \\
\hline 8 & & 91 & 99 & $>99$ & 550 \\
\hline 9 & & 46 & 57 & 87 & 150 \\
\hline 10 & & 99 & $>99$ & $>99$ & 490 \\
\hline 11 & & 62 & 80 & 96 & 310 \\
\hline 12 & & 71 & 92 & $>99$ & 360 \\
\hline 13 & & 40 & 46 & 58 & 60 \\
\hline 14 & & $<2$ & 3 & 5 & - \\
\hline 15 & & 15 & 18 & 28 & - \\
\hline 16 & & 11 & 14 & 21 & - \\
\hline $17^{c}$ & & 82 & $>99$ & $>99$ & 320 \\
\hline $18^{c}$ & & 44 & 87 & $>99$ & 180 \\
\hline
\end{tabular}


${ }^{a}$ General reaction conditions: substrate $(1 \mathrm{mmol}), \mathrm{KOH}(0.1 \mathrm{mmol}, 10 \mathrm{~mol} \%), \mathbf{2 d}(0.01 \mathrm{mmol}, 1 \mathrm{~mol} \%), i \mathrm{PrOH}$ $(5 \mathrm{~mL})$, reflux temperature, aerobic conditions; ${ }^{b}$ determined by ${ }^{1} \mathrm{H}$ NMR spectroscopy using anisole or hexamethylbenzene as internal standard, conversions correspond to yields, calculated as an average of at least two runs; ${ }^{c}$ complex $2 \mathbf{c}(0.01 \mathrm{mmol}, 1 \mathrm{~mol} \%)$ as catalyst.

Pyridyl-containing ketones are generally challenging substrates for transfer hydrogenation because the pyridyl group favorably competes with the carbonyl group for coordination to late transition metals and often inhibits substrate conversion ( $c f$ also entries 3,7). Indeed, conversion of di(2-pyridyl)ketone and the different acetylpyridines with complex 2d was only moderate to low (entries 13-16). Inspection of the timeconversion profiles reveals some interesting insights (Fig. 9). The initial conversion rates are substratedependent and therefore point to substrate inhibition of the catalytic species. By far the lowest activity was noted for 2-acetylpyridine ( $<2$ TON after $15 \mathrm{~min}$, entry 14), which is attributed to a higher stability of $N$ coordination of the substrate supported by $\mathrm{N}, \mathrm{O}$-bidentate chelation. Similar chelation is sterically disfavored in 3- and 4-acetyl pyridine and hence, these substrates are converted faster (entries 15,16). While dipyridylketone may chelate in a similar way as 2-acetylpyridine, $\mathrm{N}, \mathrm{O}$-bidentate bonding is surmised to be weakened due to the low electron density of the carbonyl group because of the two pyridyl substituents, and turnover frequencies are considerably higher ( 40 TON after 15 min, entry 13). In agreement with such a model, conversion of this substrate drops markedly after about $40 \%$ conversion, which is attributed to product inhibition as the hydrogenated product is a stronger chelate than the substrate (more basic pyridyl unit and alkoxide as stronger donor than ketone).
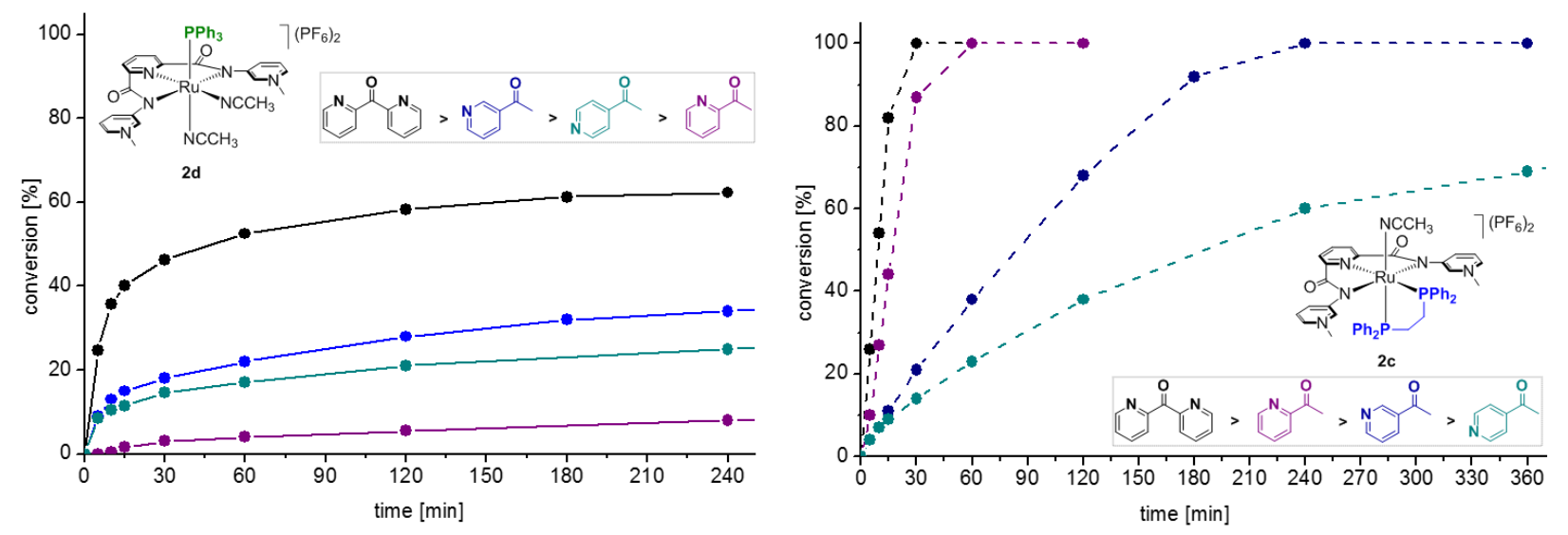

Figure 9. Time-conversion profiles for the transfer hydrogenation of pyridyl-substituted ketones with monophosphine complex 2d (left, solid lines) and diphosphine complex 2c (right, dashed lines). Reaction conditions as indicated in Table 5 . 
Based on these considerations, we used complex $\mathbf{2 c}$ which has only one substitution-labile site for substrate coordination due to the bidentate dppe ligand (entries 17-20). This complex configuration prevents chelation of the substrate or product. Indeed, conversion of 2-acetylpyridine is substantially enhanced, reaching essentially full conversion already after $30 \mathrm{~min}$ (entry 18). Similarly, inhibition with 2pyridylketone or its product dipyridylmethanol is suppressed and transfer hydrogenation is complete within 15 min (entry 17). The effect of the dppe ancillary ligand is less pronounced for 3-and 4-acetylpyridine (entries 19,20, essentially complete conversion after 4 and $24 \mathrm{~h}$, respectively), presumably because the pyridine coordination site is sterically less protected as the acetyl group is in more remote position. Hence, engineering of the ancillary ligand allows to tailor the pincer PYA ruthenium complexes for the transformation of challenging substrates.

The activity of complex $\mathbf{2 d}$ towards $\alpha, \beta$-unsaturated ketones was evaluated using methyl cinnamylketone $\mathbf{3}$ as substrate. Transfer hydrogenation produced selectively the saturated ketone 4-phenyl-2-butanone $\mathbf{4}$ as the only product within $30 \mathrm{~min}$ and the reaction composition did not alter upon extending the reaction time to several hours (Scheme 4). This outcome is distinct from most other transfer hydrogenation catalysts which either produce mixtures of products from hydrogenation of the $\mathrm{C}=\mathrm{C}$ bond, the ketone, or both, typically yielding the fully saturated product. ${ }^{58,59,60}$ For example Noyori-type catalysts are known for their carbonylselective hydrogenation of $\alpha, \beta$-unsaturated ketones. ${ }^{61}$ Only very few catalytic systems are known that selectively reduce only the $\mathrm{C}=\mathrm{C}$ bond in such Michael systems, requiring either precious metals ${ }^{62}$ or peculiar reaction conditions such as ionic liquids. ${ }^{63}$

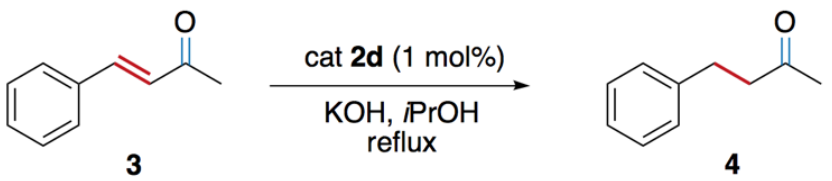

Scheme 4. Selective olefin transfer hydrogenation of methyl cinnamylketone $\mathbf{3}$ with complex $\mathbf{2 d}$ producing the saturated ketone $\mathbf{4}$ as the exclusive product.

The NMR spectra of samples taken at different time intervals only reveal the characteristic resonances of the product and the starting material, but no trace of an allyl alcohol product that would result from ketone reduction (Fig. S18). These observations suggest that either double bond isomerization is very fast, or that the catalyst is selectively reducing the conjugated $\mathrm{C}=\mathrm{C}$ bond of the substrate. The selectivity of this reduction is remarkable when considering that the product ketone is per se a suitable substrate that is converted to completion in a separate catalytic run within one hour (Table 5, entry 12; Fig. S19). The selective olefin hydrogenation of $\mathbf{3}$ therefore implies that olefin reduction of methyl cinnamylketone 
deactivates the catalytically active species. This hypothesis was verified by running a catalytic experiment using initially methyl cinnamylketone as a substrate followed by addition of acetophenone (1 molequiv.) after 30 min. Conversion of acetophenone was negligible, reaching just $5 \%$ after 6 h (Fig. S20; cf full conversion after $0.5 \mathrm{~h}$ in a separate run, Table 5 entry 2). Several attempts, to characterize the deactivated species have been unsuccessful so far, which prevents the postulation of a plausible rationale for this exquisite selectivity in the reduction of this unsaturated ketone. Similar reactivity patterns were observed with related $\alpha, \beta$-unsaturated ketones such as trans-chalcone, while 1-phenyl-2-buten-3-one was fully reduced to the saturated alcohol. However, with both substrates, considerable amounts of side products were formed due to oxidative $\mathrm{C}=\mathrm{C}$ bond cleavage (see $\mathrm{SI}$ for details).

\section{Conclusions}

Here we have designed and exploited the properties of a new $N, N, N$-tridentate pincer ligand containing zwitterionic $m$-PYA chelating groups. The distinct structural and electronic properties of these chelating groups compared to $p$-PYA systems with more pronounced valence isomerism induce significant catalytic activity of the ruthenium complexes in transfer hydrogenation, in contrast to the $p$-PYA analogue which was catalytically silent. Substitution of the ancillary ligands of the $\left[R u\left(N^{\wedge} N^{\wedge} N\right) L_{3}\right]$ complex provides a method to rationally tailor the electron density at the ruthenium(II) center and its catalytic activity. Phosphine ligands increase the catalytic activity substantially, and mechanistic investigations indicate that this enhancement is conveyed by the strong trans effect of phosphines and the ensuing lability of the $\mathrm{MeCN}$ ligand for facile substrate coordination and product release.

Moreover, the PYA pincer platform imparts stability and provides access to a molecular catalyst with appreciable turnover numbers, and unusual selectivity patterns, as demonstrated with the selective $\mathrm{C}=\mathrm{C}$ bond hydrogenation in $\alpha, \beta$-unsaturated ketones and the efficient transfer hydrogenation of 2-acetylpyridine. Due to the facile synthetic assembly and their unique properties, such PYA pincer systems provide an attractive scaffold for other metals and catalytic processes.

\section{Experimental}

General. All reagents were commercially available and used as received. Unless specified otherwise, NMR spectra were recorded at $25{ }^{\circ} \mathrm{C}$ on Bruker spectrometers operating at 300 or $400 \mathrm{MHz}\left({ }^{1} \mathrm{H} \mathrm{NMR}\right)$, and $100 \mathrm{MHz}\left({ }^{13} \mathrm{C} \mathrm{NMR}\right)$, respectively. Chemical shifts ( $\delta$ in ppm, coupling constants $J$ in $\mathrm{Hz}$ ) were referenced to residual solvent signals $\left({ }^{1} \mathrm{H},{ }^{13} \mathrm{C}\right)$. Assignments are based on homo- and heteronuclear shift correlation spectroscopy. Purity of bulk samples of the complexes has been established by NMR spectroscopy, and 
when possible by elemental analysis. Elemental analyses were performed at DCB Microanalytic Laboratory using a Thermo Scientific Flash 2000 CHNS-O elemental analyzer. High-resolution mass spectrometry was carried out with a Thermo Scientific LTQ Orbitrap XL (ESI-TOF) by the mass spectroscopy group of the Department of Chemistry and Biochemistry, University of Bern, PD Dr. S. Schürch. Gas chromatography measurements were performed on the 7697A Headspace Sampler and 7820A GC System by Agilent Technologies. The UV-1800 from Shimadzu with $1 \mathrm{~cm}$ quartz cuvettes was used for the UV/Vis measurements. Cyclic voltammograms were recorded using an Autolab PGSTAT101 from Metrohm in MeCN solutions: $10 \mathrm{ml}$ solvent, $1 \mathrm{mM}$ sample and $100 \mathrm{mM}$ tetrabutylammonium hexfluorophosphate $\left(n \mathrm{Bu}_{4} \mathrm{~N}\right) \mathrm{PF}_{6}$ as supporting electrolyte). Solutions were deaerated with argon gas for 10 min prior to each run. The scan rate was $100 \mathrm{mV} / \mathrm{s}$. Redox potentials were measured using a Pt-button working electrode, an $\mathrm{Ag} / \mathrm{AgCl}$ reference electrode (SSCE) and a Pt-wire auxiliary electrode and are tabulated versus a ferrocene internal standard. The $\mathrm{Fc}^{+} / \mathrm{Fc}$ couple is $0.43 \mathrm{~V}$ vs. SSCE in $0.1 \mathrm{M}\left(n \mathrm{Bu}_{4} \mathrm{~N}\right) \mathrm{PF}_{6} \mathrm{MeCN}$ solutions. ${ }^{64}$

\section{Synthetic procedures}

Compound L1: To a suspension of the iodide salt (1.560 g, $2.6 \mathrm{mmol})$ in MeCN (30 mL) a solution of $\mathrm{NH}_{4} \mathrm{PF}_{6}(2.119 \mathrm{~g}, 13.0 \mathrm{mmol})$ in $\mathrm{H}_{2} \mathrm{O}(60 \mathrm{~mL})$ was added under vigorous stirring. The white suspension was heated to reflux for $5 \mathrm{~min}$, which gave a clear solution. Upon slow cooling to room temperature colourless crystals formed. They were collected by filtration and washed with water and $\mathrm{Et}_{2} \mathrm{O}$ and dried under reduced pressure to give $\mathbf{L 1}$ as colourless needle-like crystals (1.564 g, 96\%). ${ }^{1} \mathrm{H}$ NMR (300 MHz, DMSO- $\left.d_{6}\right) \delta$ $11.95\left(\mathrm{~s}, 2 \mathrm{H}, \mathrm{NH}_{\text {amide }}\right), 8.87$ (d, $\left.{ }^{3} J_{\mathrm{HH}}=7.4 \mathrm{~Hz}, 4 \mathrm{H}, \mathrm{H}_{\mathrm{PYA}}\right), 8.56-8.58\left(\mathrm{~m}, 2 \mathrm{H}, \mathrm{H}_{\mathrm{pyr}}\right), 8.49\left(\mathrm{~d},{ }^{3} J_{\mathrm{HH}}=7.4 \mathrm{~Hz}\right.$, $\left.4 \mathrm{H}, \mathrm{H}_{\mathrm{PYA}}\right), 8.44-8.50\left(\mathrm{~m}, 1 \mathrm{H}, \mathrm{H}_{\mathrm{pyr}}\right), 4.26\left(\mathrm{~s}, 6 \mathrm{H}, \mathrm{N}-\mathrm{CH}_{3}\right) .{ }^{13} \mathrm{C} \mathrm{NMR}\left(101 \mathrm{MHz}, \mathrm{DMSO}-d_{6}\right) \delta 163.3(\mathrm{CO})$, $150.8\left(\mathrm{C}_{\mathrm{pyr}}\right), 147.2\left(\mathrm{C}_{\mathrm{pyr}}\right), 146.2\left(\mathrm{CH}_{\mathrm{pyr}}\right), 141.0\left(\mathrm{CH}_{\mathrm{pyr}}\right), 127.3\left(\mathrm{CH}_{\mathrm{pyr}}\right), 116.0\left(\mathrm{CH}_{\mathrm{pyr}}\right), 46.7\left(\mathrm{~N}-\mathrm{CH}_{3}\right)$. ESI MS $\left(\mathrm{CH}_{3} \mathrm{CN}\right) \mathrm{m} / \mathrm{z}: 494.12\left[\mathrm{M}-\mathrm{PF}_{6}\right]^{+}, 348.15\left[\mathrm{M}-2 \mathrm{PF}_{6}-\mathrm{H}\right]^{+}$. HR-MS: $\mathrm{m} / \mathrm{z}$ calculated for $\mathrm{C}_{19} \mathrm{H}_{19} \mathrm{O}_{2} \mathrm{~N}_{5} \mathrm{~F}_{6} \mathrm{P}[\mathrm{M}-$ $\left.\mathrm{PF}_{6}\right]^{+}=494.1151$; found: 494.1175. Elemental Analysis: Anal. calculated for $\mathrm{C}_{19} \mathrm{H}_{19} \mathrm{~F}_{12} \mathrm{~N}_{5} \mathrm{O}_{2} \mathrm{P}_{2}: \mathrm{C}: 35.70$; H: $3.00 ; \mathrm{N}: 10.95$. Found: C: 35.63; H: 3.85; N: 10.69.

Compound L2: This product was prepared according to the same procedure as described for $\mathbf{L} 1$ from the iodide salt X2 (1.808 g, $3.0 \mathrm{mmol})$ in $\mathrm{MeCN}(50 \mathrm{~mL})$ and $\mathrm{NH}_{4} \mathrm{PF}_{6}(2.458 \mathrm{~g}, 15.0 \mathrm{mmol})$ in $\mathrm{H}_{2} \mathrm{O}(100 \mathrm{ml})$, which afforded $\mathbf{L 2}$ as colourless crystals (1.863 g, 97\%). ${ }^{1} \mathrm{H}$ NMR (300 MHz, DMSO-d $) \delta 11.67$ (s, 2H, $\mathrm{NH}_{\text {amide }}$ ), 9.72 (s, 2H, $\left.\mathrm{H}_{\mathrm{PYA}}\right), 8.85\left(\mathrm{~d},{ }^{3} J_{\mathrm{HH}}=8.6,2 \mathrm{H}, \mathrm{H}_{\mathrm{PYA}}\right), 8.82\left(\mathrm{~d},{ }^{3} J_{\mathrm{HH}}=6.0,2 \mathrm{H}, \mathrm{H}_{\mathrm{PYA}}\right), 8.53-8.55(\mathrm{~m}$, $\left.2 \mathrm{H}, \mathrm{H}_{\mathrm{pyr}}\right), 8.43-8.47\left(\mathrm{~m}, 1 \mathrm{H}, \mathrm{H}_{\mathrm{pyr}}\right), 8.23\left(\mathrm{dd},{ }^{3} \mathrm{~J}_{\mathrm{HH}}=8.6,6.0 \mathrm{~Hz}, 2 \mathrm{H}, \mathrm{H}_{\mathrm{PYA}}\right), 4.47\left(\mathrm{~s}, 6 \mathrm{H}, \mathrm{N}-\mathrm{CH}_{3}\right) .{ }^{13} \mathrm{C} \mathrm{NMR}$ $\left(101 \mathrm{MHz}, \mathrm{DMSO}-d_{6}\right) \delta 162.4(\mathrm{CO}), 147.3\left(\mathrm{C}_{\mathrm{pyr}}\right), 141.1\left(\mathrm{CH}_{\mathrm{pyr}}\right), 141.0\left(\mathrm{CH}_{\mathrm{pyr}}\right), 137.9\left(\mathrm{C}_{\mathrm{pyr}}\right), 136.4\left(\mathrm{CH}_{\mathrm{pyr}}\right)$, $135.1\left(\mathrm{CH}_{\text {pyr }}\right), 127.9\left(\mathrm{CH}_{\text {pyr }}\right), 126.6\left(\mathrm{CH}_{\text {pyr }}\right), 48.7\left(\mathrm{~N}-\mathrm{CH}_{3}\right)$. ESI MS $\left(\mathrm{CH}_{3} \mathrm{CN}\right) \mathrm{m} / \mathrm{z}: 494.12\left[\mathrm{M}-\mathrm{PF}_{6}\right]_{+}$, 174.58 $\left[\mathrm{M}-2 \mathrm{PF}_{6}\right]^{2+}$. Elemental Analysis: Anal. calculated for $\mathrm{C}_{19} \mathrm{H}_{19} \mathrm{~F}_{12} \mathrm{~N}_{5} \mathrm{O}_{2} \mathrm{P}_{2}: \mathrm{C}: 35.70 ; \mathrm{H}: 3.00 ; \mathrm{N}: 10.95$. Found: C: 35.66 ; H: 3.00; N: 10.89. 
Complex 1: A solution of $\mathbf{L 1}(130 \mathrm{mg}, 0.20 \mathrm{mmol}),\left[\mathrm{RuCl}_{2}(\mathrm{cym})\right]_{2}(60 \mathrm{mg}, 0.10 \mathrm{mmol})$ and $\mathrm{Na}_{2} \mathrm{CO}_{3}$ $(65 \mathrm{mg}, 0.60 \mathrm{mmol})$ in $\mathrm{MeCN}(50 \mathrm{~mL})$ was stirred at reflux for $16 \mathrm{~h}$. The reaction mixture changed colour from orange to deep red. After cooling to rt, the reaction mixture was filtered over Celite and the red solution was concentrated under reduced pressure to $5 \mathrm{~mL}$. Addition of $\mathrm{Et}_{2} \mathrm{O}(100 \mathrm{~mL})$ gave a dark red precipitate which was collected by filtration and redisolved in $\mathrm{MeCN}(10 \mathrm{~mL})$, filtered over Celite and precipitated again by addition of $\mathrm{Et}_{2} \mathrm{O}(100 \mathrm{~mL})$. The product was collected by filtration and drying of the residue under reduced pressure yielded the complex as a red-brown powder $1(157 \mathrm{mg}, 91 \%) .{ }^{1} \mathrm{H}$ NMR $(300 \mathrm{MHz}$, DMSO- $\left.d_{6}\right) \delta 8.52\left(\mathrm{~d},{ }^{3} J_{\mathrm{HH}}=7.3 \mathrm{~Hz}, 4 \mathrm{H}, \mathrm{H}_{\mathrm{PYA}}\right), 8.19-8.21\left(\mathrm{~m}, 3 \mathrm{H}, \mathrm{H}_{\mathrm{pyr}}\right), 7.91\left(\mathrm{~d},{ }^{3} J_{\mathrm{HH}}=7.3 \mathrm{~Hz}, 4 \mathrm{H}, \mathrm{H}_{\mathrm{PYA}}\right)$, $4.13\left(\mathrm{~s}, 6 \mathrm{H}, \mathrm{N}-\mathrm{CH}_{3}\right), 2.76\left(\mathrm{~s}, 3 \mathrm{H}, \mathrm{NCCH}_{3}\right), 2.34\left(\mathrm{~s}, 6 \mathrm{H}, \mathrm{NCCH}_{3}\right) .{ }^{13} \mathrm{C} \mathrm{NMR}\left(101 \mathrm{MHz}, \mathrm{DMSO}-d_{6}\right) \delta 170.9$ (CO), $164.3\left(\mathrm{C}_{\mathrm{pyr}}\right), 153.9\left(\mathrm{C}_{\mathrm{pyr}}\right), 144.1\left(\mathrm{CH}_{\mathrm{pyr}}\right), 139.1\left(\mathrm{CH}_{\mathrm{pyr}}\right), 130.8(\mathrm{NCMe}), 128.1\left(\mathrm{CH}_{\mathrm{pyr}}\right), 122.7\left(\mathrm{CH}_{\mathrm{pyr}}\right)$, $118.1(\mathrm{NCMe}), 45.9\left(\mathrm{~N}-\mathrm{CH}_{3}\right), 4.7\left(\mathrm{NCCH}_{3}\right), 1.1\left(\mathrm{NCCH}_{3}\right)$. HR-MS: m/z calculated for $\mathrm{C}_{23} \mathrm{H}_{23} \mathrm{O}_{2} \mathrm{~N}_{7} \mathrm{~F}_{6} \mathrm{PRu}$ $\left[\mathrm{M}-\mathrm{PF}_{6}-\mathrm{MeCN}\right]^{+}=676.0590$; found: 676.0593. Elemental Analysis: anal. calculated for $\mathrm{C}_{25} \mathrm{H}_{26} \mathrm{~F}_{12} \mathrm{~N}_{8} \mathrm{O}_{2} \mathrm{P}_{2} \mathrm{Ru}: \mathrm{C}: 34.85 ; \mathrm{H}: 3.04 ; \mathrm{N}: 13.01$. Found: C: 34.86; H: 3.02; N: 12.71.

Complex 2a: This complex was synthesized according to the same procedure as described for complex 1 starting from $\mathbf{L 2}$ (419 mg, $0.645 \mathrm{mmol}),\left[\mathrm{RuCl}_{2}(\mathrm{cym})\right]_{2}(201 \mathrm{mg}, 0.335 \mathrm{mmol})$, and $\mathrm{Na}_{2} \mathrm{CO}_{3}(218 \mathrm{mg}, 2.0$ $\mathrm{mmol})$ in $\mathrm{MeCN}(150 \mathrm{~mL})$ and was obtained as a red crystalline powder $(505 \mathrm{mg}, 96 \%)$. ${ }^{1} \mathrm{H}$ NMR $\left(300 \mathrm{MHz}, \mathrm{DMSO}-d_{6}\right) \delta 9.07$ (s, 2H, $\left.\mathrm{H}_{\mathrm{PYA}}\right), 8.55\left(\mathrm{~d},{ }^{3} J_{\mathrm{HH}}=5.9 \mathrm{~Hz}, 2 \mathrm{H}, \mathrm{H}_{\mathrm{PYA}}\right), 8.32\left(\mathrm{~d},{ }^{3} J_{\mathrm{HH}}=9.0 \mathrm{~Hz}, 2 \mathrm{H}\right.$, $\left.\mathrm{H}_{\mathrm{PYA}}\right), 8.10-8.20\left(\mathrm{~m}, 3 \mathrm{H}, \mathrm{H}_{\mathrm{pyr}}\right), 8.01\left(\mathrm{dd},{ }^{3} J_{\mathrm{HH}}=9.0,5.9 \mathrm{~Hz}, 2 \mathrm{H}, \mathrm{H}_{\mathrm{PYA}}\right), 4.37\left(\mathrm{~s}, 6 \mathrm{H}, \mathrm{N}-\mathrm{CH}_{3}\right), 2.65(\mathrm{~s}, 3 \mathrm{H}$, $\left.\mathrm{NCCH}_{3}\right), 2.34$ (s, 6H, NCCH 3$) .{ }^{13} \mathrm{C}$ NMR (101 MHz, DMSO- $\left.d_{6}\right) \delta 169.4(\mathrm{CO}), 153.6\left(\mathrm{C}_{\mathrm{pyr}}\right), 151.8\left(\mathrm{C}_{\mathrm{pyr}}\right)$, $144.0\left(\mathrm{CH}_{\mathrm{pyr}}\right), 143.0\left(\mathrm{CH}_{\mathrm{pyr}}\right), 139.9\left(\mathrm{CH}_{\mathrm{pyr}}\right), 139.5\left(\mathrm{CH}_{\mathrm{pyr}}\right), 127.2\left(\mathrm{CH}_{\mathrm{pyr}}\right), 125.3\left(\mathrm{CH}_{\mathrm{pyr}}\right), 125.1(\mathrm{NCMe})$, $118.1(\mathrm{NCMe}), 47.7\left(\mathrm{~N}-\mathrm{CH}_{3}\right), 3.8\left(\mathrm{NCCH}_{3}\right), 1.1\left(\mathrm{NCCH}_{3}\right)$. HR-MS: $\mathrm{m} / \mathrm{z}$ calculated for $\mathrm{C}_{25} \mathrm{H}_{26} \mathrm{~F}_{6} \mathrm{~N}_{8} \mathrm{O}_{2} \mathrm{PRu}$ $\left[\mathrm{M}-\mathrm{PF}_{6}\right]^{+}=717.0862$; found: 717.0859. Elemental Analysis: anal. calculated for $\mathrm{C}_{25} \mathrm{H}_{26} \mathrm{~F}_{12} \mathrm{~N}_{8} \mathrm{O}_{2} \mathrm{P}_{2} \mathrm{Ru}$ : C: 34.85, H: 3.04, N: 13.01. Found: C: 35.50, H: 3.63, N: 12.50 .

General procedure for the synthesis of complexes $\mathbf{2 b - f}$. Compound $2 \mathbf{2}$ (1.0 eq.) and the indicated ligand were dissolved in EtOH $(50 \mathrm{~mL})$ and heated to reflux at $90{ }^{\circ} \mathrm{C}$ for $16 \mathrm{~h}$. The mixture was cooled to $\mathrm{rt}$ and evaporated to dryness. The residue was dissolved in a minimum amount of $\mathrm{MeCN}$ and precipitated by addition of $\mathrm{Et}_{2} \mathrm{O}$. The precipitate was filtered, and washed with $\mathrm{Et}_{2} \mathrm{O}$, and dried in vacuo to yield the title complex as a crystalline powder.

Complex 2b: According to the general procedure from 2a (97 mg, $0.113 \mathrm{mmol}, 1.0$ eq.) and 1,1bis(diphenylphosphino)methane (92 $\mathrm{mg}, 0.120 \mathrm{mmol}$,). Compound $\mathbf{2 b}$ was obtained as orange crystalline powder (106 mg, 79\%). ${ }^{1} \mathrm{H}$ NMR (400 MHz, MeCN-d $) \delta 8.35-8.39\left(\mathrm{~m}, 1 \mathrm{H}, \mathrm{H}_{\mathrm{pyr}}\right), 8.27-8.29\left(\mathrm{~m}, 2 \mathrm{H}, \mathrm{H}_{\mathrm{pyr}}\right)$,

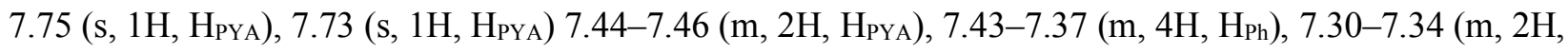
$\left.\mathrm{H}_{\mathrm{PYA}}\right), 7.27-7.18\left(\mathrm{~m}, 8 \mathrm{H}, \mathrm{H}_{\mathrm{Ph}}\right), 7.16-7.05\left(\mathrm{~m}, 8 \mathrm{H}, \mathrm{H}_{\mathrm{Ph}}\right), 6.94-6.98\left(\mathrm{~m}, 2 \mathrm{H}, \mathrm{H}_{\mathrm{PYA}}\right), 4.72\left(\mathrm{~d},{ }^{2} J_{\mathrm{HH}}=10.1 \mathrm{~Hz}\right.$, $\left.1 \mathrm{H}, \mathrm{CH}_{2}\right), 4.69\left(\mathrm{~d},{ }^{2} J_{\mathrm{HH}}=10.1 \mathrm{~Hz}, 1 \mathrm{H}, \mathrm{CH}_{2}\right), 3.85\left(\mathrm{~s}, 6 \mathrm{H}, \mathrm{N}-\mathrm{CH}_{3}\right) .{ }^{13} \mathrm{C} \mathrm{NMR}\left(101 \mathrm{MHz}, \mathrm{MeCN}-d_{3}\right) \delta 170.3$ 
(CO), $154.6\left(\mathrm{C}_{\mathrm{pyr}}\right), 152.5\left(\mathrm{C}_{\mathrm{pyr}}\right), 143.8\left(\mathrm{CH}_{\mathrm{pyr}}\right), 143.2\left(\mathrm{CH}_{\mathrm{pyr}}\right), 139.7\left(\mathrm{CH}_{\mathrm{pyr}}\right), 139.2\left(\mathrm{CH}_{\mathrm{pyr}}\right), 134.7\left({ }^{1} J_{\mathrm{CP}}=37\right.$ $\left.\mathrm{Hz},{ }^{3} J_{\mathrm{CP}}=4.2 \mathrm{~Hz}, \mathrm{C}_{\mathrm{Ph}}\right), 134.3\left({ }^{1} J_{\mathrm{CP}}=33 \mathrm{~Hz},{ }^{3} J_{\mathrm{CP}}=3.6 \mathrm{~Hz}, \mathrm{C}_{\mathrm{Ph}}\right), 132.1\left(J_{\mathrm{CP}}=11.2 \mathrm{~Hz}, \mathrm{CH}_{\mathrm{Ph}}\right), 131.8\left(J_{\mathrm{CP}}=\right.$ $\left.2.6 \mathrm{~Hz}, \mathrm{CH}_{\mathrm{Ph}}\right), 131.4\left(J_{\mathrm{CP}}=10.3 \mathrm{~Hz}, \mathrm{CH}_{\mathrm{Ph}}\right), 131.2\left(J_{\mathrm{CP}}=2.4 \mathrm{~Hz}, \mathrm{CH}_{\mathrm{Ph}}\right), 130.4\left(J_{\mathrm{CP}}=10.0 \mathrm{~Hz}, \mathrm{CH}_{\mathrm{Ph}}\right), 129.9$ $\left(J_{\mathrm{CP}}=9.7 \mathrm{~Hz}, \mathrm{CH}_{\mathrm{Ph}}\right), 128.0\left(\mathrm{CH}_{\mathrm{pyr}}\right), 127.1\left(\mathrm{CH}_{\mathrm{pyr}}\right), 48.9\left(\mathrm{~N}-\mathrm{CH}_{3}\right), 43.0\left(\mathrm{t},{ }^{1} J_{\mathrm{CP}}=26 \mathrm{~Hz}, \mathrm{CH}_{2}\right) .{ }^{31} \mathrm{P}\left\{{ }^{1} \mathrm{H}\right\} \mathrm{NMR}$ $\left(162 \mathrm{MHz}, \mathrm{MeCN}-d_{3}\right) \delta 0.14\left(\mathrm{~d},{ }^{2} J_{\mathrm{PP}}=57.8 \mathrm{~Hz}, 1 \mathrm{P}, \mathrm{dppm}\right),-3.24\left(\mathrm{~d},{ }^{2} J_{\mathrm{PP}}=57.8 \mathrm{~Hz}, 1 \mathrm{P}, \mathrm{dppm}\right),-144.59$ (hept, ${ }^{1} J_{\mathrm{PF}}=708 \mathrm{~Hz}, 2 \mathrm{P}, \mathrm{PF}_{6}$ ). HR-MS: $\mathrm{m} / \mathrm{z}$ calculated for $\mathrm{C}_{44} \mathrm{H}_{39} \mathrm{O}_{2} \mathrm{~N}_{5} \mathrm{~F}_{6} \mathrm{P}_{3} \mathrm{Ru}\left[\mathrm{M}-\mathrm{PF}_{6}-\mathrm{MeCN}\right]^{+}=978.1259$; found 978.1259. Elemental Analysis: anal. calculated for $\mathrm{C}_{46} \mathrm{H}_{42} \mathrm{~F}_{12} \mathrm{~N}_{6} \mathrm{O}_{2} \mathrm{P}_{4} \mathrm{Ru} \times \mathrm{H}_{2} \mathrm{O}$ : C: 46.75, H: 3.75, N: 7.11. Found: C: 46.70, H: 4.13, N: 6.90.

Complex 2c: According to general procedures with compound 2a (117 mg, $0.136 \mathrm{mmol}, 1.0$ eq.) and 1,2-bis(diphenylphosphino)ethane (56 mg, $0.141 \mathrm{mmol}, 1.0 \mathrm{eq}$.). Compound $2 \mathrm{c}$ was obtained as orange crystalline powder (137 mg, $0.116 \mathrm{mmol}, 99 \%$ yield). ${ }^{1} \mathrm{H}$ NMR $\left(300 \mathrm{MHz}, \mathrm{DMSO}-d_{6}\right) \delta 8.50\left(\mathrm{t},{ }^{3} J_{\mathrm{HH}}=7.8\right.$ $\left.\mathrm{Hz}, 1 \mathrm{H}, \mathrm{H}_{\mathrm{pyr}}\right), 8.26\left(\mathrm{~d},{ }^{3} J_{\mathrm{HH}}=7.8 \mathrm{~Hz}, 2 \mathrm{H}, \mathrm{H}_{\text {pyr }}\right), 8.06\left(\mathrm{~d},{ }^{3} J_{\mathrm{HH}}=6.9 \mathrm{~Hz}, 2 \mathrm{H}, \mathrm{H}_{\mathrm{PYA}}\right), 7.66\left(\mathrm{~s}, 2 \mathrm{H}, \mathrm{H}_{\mathrm{PYA}}\right), 7.31$ $\left(\mathrm{dd},{ }^{3} J_{\mathrm{HH}}=6.9,8.4 \mathrm{~Hz}, 2 \mathrm{H}, \mathrm{H}_{\mathrm{PYA}}\right), 7.28-7.16\left(\mathrm{~m}, 14 \mathrm{H}, \mathrm{H}_{\mathrm{Ph}}\right), 7.06-7.02\left(\mathrm{~m}, 6 \mathrm{H}, \mathrm{H}_{\mathrm{Ph}}\right), 6.81\left(\mathrm{~d},{ }^{3} J_{\mathrm{HH}}=8.4 \mathrm{~Hz}\right.$,

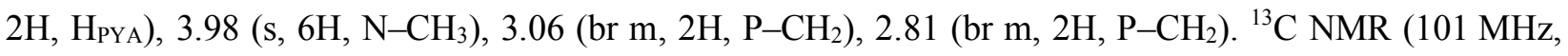
DMSO-d $)_{6} \delta 170.5(\mathrm{CO}), 154.1\left(\mathrm{C}_{\mathrm{pyr}}\right), 150.8\left(\mathrm{C}_{\mathrm{pyr}}\right), 142.9\left(\mathrm{CH}_{\mathrm{pyr}}\right), 140.5\left(\mathrm{CH}_{\mathrm{pyr}}\right), 139.5\left(\mathrm{CH}_{\mathrm{pyr}}\right), 138.2$ $\left(\mathrm{CH}_{\mathrm{pyr}}\right), 134.9\left({ }^{1} J_{\mathrm{CP}}=36 \mathrm{~Hz}, \mathrm{C}_{\mathrm{Ph}}\right), 130.8\left(\mathrm{CH}_{\mathrm{pyr}}\right), 130.2\left(J_{\mathrm{CP}}=8.1 \mathrm{~Hz}, \mathrm{CH}_{\mathrm{Ph}}\right), 128.9\left(J_{\mathrm{CP}}=9.5 \mathrm{~Hz}, \mathrm{CH}_{\mathrm{Ph}}\right)$, $128.2\left(J_{\mathrm{CP}}=8.9 \mathrm{~Hz}, \mathrm{CH} \mathrm{Ph}\right), 126.7\left(\mathrm{CH}_{\mathrm{pyr}}\right), 114.5(\mathrm{NCMe}), 47.4\left(\mathrm{~N}-\mathrm{CH}_{3}\right), 24.0\left(\mathrm{P}-\mathrm{CH}_{2}\right), 22.0\left(\mathrm{P}-\mathrm{CH}_{2}\right), 1.1$ $\left(\mathrm{NCCH}_{3}\right) .{ }^{31} \mathrm{P}$ NMR $\left(162 \mathrm{MHz}, \mathrm{DMSO}-d_{6}\right) \delta 66.23\left(\mathrm{~d},{ }^{3} J_{\mathrm{PP}}=13.8 \mathrm{~Hz}, 1 \mathrm{P}, \mathrm{dppe}\right), 54.25\left(\mathrm{~d},{ }^{3} J_{\mathrm{PP}}=13.8 \mathrm{~Hz}\right.$, 1P, dppe), -144.17 (hept, ${ }^{1} J_{\mathrm{PF}}=711 \mathrm{~Hz}, 2 \mathrm{P}, \mathrm{PF}_{6}$ ). HR-MS: m/z calculated for $\mathrm{C}_{45} \mathrm{H}_{41} \mathrm{O}_{2} \mathrm{~N}_{5} \mathrm{~F}_{6} \mathrm{P}_{3} \mathrm{Ru}\left[\mathrm{M}-\mathrm{PF}_{6}-\right.$ $\mathrm{MeCN}]^{+}=992.1415$; found: 992.1430. Elemental Analysis: anal. calculated for $\mathrm{C}_{47} \mathrm{H}_{44} \mathrm{~F}_{12} \mathrm{~N}_{6} \mathrm{O}_{2} \mathrm{P}_{4} \mathrm{Ru} \times \mathrm{H}_{2} \mathrm{O}$ : C: 47.21, H: 3.88, N: 7.03. Found: C: 47.19, H: 4.29, N: 6.79.

Complex 2d: According to general procedures with compound 2a (96 mg, $0.111 \mathrm{mmol}, 1.0$ eq.) and triphenylphosphine (31 mg, $0.118 \mathrm{mmol}, 1.0$ eq.). Compound $2 \mathbf{d}$ was obtained as red crystalline powder (100 mg, $0.077 \mathrm{mmol}, 66 \%$ yield). ${ }^{1} \mathrm{H}$ NMR (400 MHz, MeCN-d $) \delta 8.33$ (s, 2H, $\left.\mathrm{H}_{\mathrm{PYA}}\right), 8.24\left(\mathrm{~d},{ }^{3} J_{\mathrm{HH}}=8.5\right.$, $\left.2 \mathrm{H}, \mathrm{H}_{\mathrm{PYA}}\right), 8.18\left(\mathrm{~d},{ }^{3} J_{\mathrm{HH}}=6.0,2 \mathrm{H}, \mathrm{H}_{\mathrm{PYA}}\right), 7.88\left(\mathrm{dd},{ }^{3} J_{\mathrm{HH}}=8.5,6.0 \mathrm{~Hz}, 2 \mathrm{H}, \mathrm{H}_{\mathrm{PYA}}\right), 7.76\left(\mathrm{t},{ }^{3} J_{\mathrm{HH}}=7.7 \mathrm{~Hz}, 1 \mathrm{H}\right.$, $\left.\mathrm{H}_{\mathrm{pyr}}\right), 7.60\left(\mathrm{~d},{ }^{3} J_{\mathrm{HH}}=7.7 \mathrm{~Hz}, 2 \mathrm{H}, \mathrm{H}_{\mathrm{pyr}}\right), 7.24-7.28\left(\mathrm{~m}, 3 \mathrm{H}, \mathrm{H}_{\mathrm{Ph}}\right), 6.99-7.04\left(\mathrm{~m}, 6 \mathrm{H}, \mathrm{H}_{\mathrm{Ph}}\right), 6.89-6.94(\mathrm{~m}, 6 \mathrm{H}$, $\left.\mathrm{H}_{\mathrm{Ph}}\right), 4.13$ (s, 6H, N-CH $), 2.67$ (s, 3H, NCCH3). ${ }^{13} \mathrm{C}$ NMR (101 MHz, MeCN-d $) \delta 170.3$ (CO), 156.1 $\left(\mathrm{C}_{\mathrm{pyr}}\right), 152.6\left(\mathrm{C}_{\mathrm{pyr}}\right), 143.8\left(\mathrm{CH}_{\mathrm{pyr}}\right), 142.2\left(\mathrm{CH}_{\mathrm{pyr}}\right), 138.1\left(\mathrm{CH}_{\mathrm{pyr}}\right), 136.9\left(\mathrm{CH}_{\mathrm{pyr}}\right), 133.5\left(J_{\mathrm{CP}}=10.6 \mathrm{~Hz}, \mathrm{CH}\right.$ Ph $)$, $132.5\left({ }^{1} J_{\mathrm{CP}}=45 \mathrm{~Hz}, \mathrm{C}_{\mathrm{Ph}}\right), 130.7\left(J_{\mathrm{CP}}=2.3 \mathrm{~Hz}, \mathrm{CH}_{\mathrm{Ph}}\right), 129.0\left(J_{\mathrm{CP}}=9.3 \mathrm{~Hz}, \mathrm{CH}_{\mathrm{Ph}}\right), 128.1\left(\mathrm{CH}_{\mathrm{pyr}}\right), 126.9$ $\left(\mathrm{CH}_{\mathrm{pyr}}\right), 49.0\left(\mathrm{~N}-\mathrm{CH}_{3}\right), 5.4\left(\mathrm{NCCH}_{3}\right) .{ }^{31} \mathrm{P} \mathrm{NMR}\left(162 \mathrm{MHz}, \mathrm{MeCN}-d_{3}\right) \delta 51.6\left(\mathrm{~s}, 1 \mathrm{P}, \mathrm{PPh}_{3}\right),-144.62($ hept, ${ }^{1} J_{\mathrm{PF}}=707 \mathrm{~Hz}, 2 \mathrm{P}, \mathrm{PF}_{6}$ ). HR-MS: m/z calculated for $\mathrm{C}_{37} \mathrm{H}_{32} \mathrm{O}_{2} \mathrm{~N}_{5} \mathrm{~F}_{6} \mathrm{P}_{2} \mathrm{Ru}\left[\mathrm{M}-\mathrm{PF}_{6}-2 \mathrm{MeCN}\right]^{+}=856.0973$; found 856.0985. Elemental Analysis: anal. calculated for $\mathrm{C}_{41} \mathrm{H}_{38} \mathrm{~F}_{12} \mathrm{~N}_{7} \mathrm{O}_{2} \mathrm{P}_{3} \mathrm{Ru}$ : C: 45.48, H: 3.54, N: 9.06. Found: C: 44.67, H: 4.81, N: 9.01. 
Complex 2e: According to general procedures with compound 2a (105 mg, $0.122 \mathrm{mmol}, 1.0 \mathrm{eq}$.) and ethylenediamine (10 $\mu 1,0.150 \mathrm{mmol}, 1.3$ eq.). Compound $\mathbf{2 e}$ was obtained as a brown crystalline powder (90 mg, $0.107 \mathrm{mmol}, 93 \%$ yield). ${ }^{1} \mathrm{H}$ NMR (300 MHz, DMSO- $\left.d_{6}\right) \delta 8.55\left(\mathrm{~d},{ }^{3} \mathrm{~J}_{\mathrm{HH}}=6.0 \mathrm{~Hz}, 2 \mathrm{H}, \mathrm{H}_{\mathrm{PYA}}\right), 8.48$ (s, 2H, HPYA $), 8.27\left(\mathrm{~d},{ }^{3} J_{\mathrm{HH}}=8.4 \mathrm{~Hz}, 2 \mathrm{H}, \mathrm{H}_{\mathrm{PYA}}\right), 7.91\left(\mathrm{dd},{ }^{3} J_{\mathrm{HH}}=8.4,6.0 \mathrm{~Hz}, 2 \mathrm{H}, \mathrm{H}_{\mathrm{PYA}}\right), 7.87-7.90(\mathrm{~m}, 2 \mathrm{H}$, $\mathrm{H}_{\mathrm{pyr}}$ ), 7.79-7.84 (m, 1H, $\mathrm{H}_{\mathrm{pyr}}$ ), 4.50 (br s, 2H, NH ), 4.32 (s, 6H, N-CH $), 2.47$ (s, 3H, NCCH $), 2.06$ (br m, $\left.2 \mathrm{H}, \mathrm{CH}_{2}\right), 1.89$ (br m, 2H, CH$\left.{ }_{2}\right) .{ }^{13} \mathrm{C}$ NMR (101 MHz, DMSO-d $) \delta 171.3(\mathrm{CO}), 156.2\left(\mathrm{C}_{\mathrm{pyr}}\right), 151.3\left(\mathrm{C}_{\mathrm{pyr}}\right)$, $142.4\left(\mathrm{CH}_{\text {pyr }}\right), 141.5\left(\mathrm{CH}_{\mathrm{pyr}}\right), 138.3\left(\mathrm{CH}_{\mathrm{pyr}}\right), 135.8\left(\mathrm{CH}_{\mathrm{pyr}}\right), 127.8\left(\mathrm{CH}_{\mathrm{pyr}}\right), 126.6\left(\mathrm{CH}_{\mathrm{pyr}}\right), 48.6\left(\mathrm{~N}-\mathrm{CH}_{3}\right), 45.7$ $\left(\mathrm{CH}_{2}\right), 44.0\left(\mathrm{CH}_{2}\right), 1.6\left(\mathrm{NCCH}_{3}\right)$. HR-MS: $\mathrm{m} / \mathrm{z}$ calculated for $\mathrm{C}_{23} \mathrm{H}_{28} \mathrm{O}_{2} \mathrm{~N}_{8} \mathrm{~F}_{6} \mathrm{PRu}\left[\mathrm{M}-\mathrm{PF}_{6}\right]^{+}=695.1015$; found: 695.1032. Elemental Analysis: anal. calculated for $\mathrm{C}_{23} \mathrm{H}_{26} \mathrm{~F}_{12} \mathrm{~N}_{8} \mathrm{O}_{2} \mathrm{P}_{2} \mathrm{Ru}: \mathrm{C}: 32.98, \mathrm{H}: 3.13$, N: 13.38 . Found: C: $33.48, \mathrm{H}: 4.62, \mathrm{~N}: 13.23$.

Complex 2f: According to general procedures with compound 2a (100 mg, $0.116 \mathrm{mmol}, 1.0$ eq.) and 4picoline ( $20 \mu 1,0.232 \mathrm{mmol}, 2.0$ eq.). Compound $\mathbf{2 f}$ was obtained as a black powder $(95 \mathrm{mg}, 0.098 \mathrm{mmol}$, $85 \%$ yield). ${ }^{1} \mathrm{H}$ NMR (300 MHz, DMSO- $\left.d_{6}\right) \delta 9.08$ (s, 2H, $\left.\mathrm{H}_{\mathrm{PYA}}\right), 8.56\left(\mathrm{~d},{ }^{3} J_{\mathrm{HH}}=5.7 \mathrm{~Hz}, 2 \mathrm{H}, \mathrm{H}_{\mathrm{PYA}}\right), 8.02-$ $8.08\left(\mathrm{~m}, 3 \mathrm{H}, \mathrm{H}_{\mathrm{pyr}}\right), 7.91\left(\mathrm{dd},{ }^{3} J_{\mathrm{HH}}=8.6,5.7 \mathrm{~Hz}, 2 \mathrm{H}, \mathrm{H}_{\mathrm{PYA}}\right), 7.78\left(\mathrm{~d},{ }^{3} J_{\mathrm{HH}}=8.6 \mathrm{~Hz}, 2 \mathrm{H}, \mathrm{H}_{\mathrm{PYA}}\right), 7.69\left(\mathrm{~d},{ }^{3} J_{\mathrm{HH}}\right.$ $\left.=6.6 \mathrm{~Hz}, 4 \mathrm{H}, \mathrm{H}_{4-\mathrm{pic}}\right), 7.06\left(\mathrm{~d},{ }^{3} J_{\mathrm{HH}}=6.6 \mathrm{~Hz}, 4 \mathrm{H}, \mathrm{H}\right.$ 4-pic $), 4.33\left(\mathrm{~s}, 6 \mathrm{H}, \mathrm{N}-\mathrm{CH}_{3}\right), 2.67\left(\mathrm{~s}, 3 \mathrm{H}, \mathrm{NCCH}_{3}\right), 2.26$ (s, 6H, $\mathrm{CH}_{3} 4$-pic $) .{ }^{13} \mathrm{C} \mathrm{NMR}\left(101 \mathrm{MHz}, \mathrm{DMSO}-d_{6}\right) \delta 169.8(\mathrm{CO}), 156.6\left(\mathrm{C}_{\mathrm{pyr}}\right), 152.4\left(\mathrm{CH}_{4-\mathrm{Pic}}\right), 149.4\left(\mathrm{C}_{\mathrm{pyr}}\right)$, $148.0\left(\mathrm{C}_{4-\text { pic }}\right), 141.6\left(\mathrm{CH}_{\mathrm{pyr}}\right), 139.5\left(\mathrm{CH}_{\mathrm{pyr}}\right), 137.7\left(\mathrm{CH}_{\mathrm{pyr}}\right), 134.8\left(\mathrm{CH}_{\mathrm{pyr}}\right), 129.9(\mathrm{NCMe}), 127.1\left(\mathrm{CH}_{\mathrm{pyr}}\right)$, $126.5\left(\mathrm{CH}_{\mathrm{pyr}}\right), 125.9(\mathrm{CH}$ 4-pic $), 47.9\left(\mathrm{~N}-\mathrm{CH}_{3}\right), 20.2\left(\mathrm{CH}_{3}\right.$ 4-Pic $), 4.2\left(\mathrm{NCCH}_{3}\right) . \mathrm{HR}-\mathrm{MS}: \mathrm{m} / \mathrm{z}$ calculated for $\mathrm{C}_{33} \mathrm{H}_{34} \mathrm{O}_{2} \mathrm{~N}_{8} \mathrm{~F}_{6} \mathrm{PRu}$ [M-PF$]^{+}=821.1485$; found: 821.1528. Elemental Analysis: anal. calculated for $\mathrm{C}_{33} \mathrm{H}_{34} \mathrm{~F}_{12} \mathrm{~N}_{8} \mathrm{O}_{2} \mathrm{P}_{2} \mathrm{Ru}$ : C: 41.04, $\mathrm{H}: 3.55, \mathrm{~N}: 11.60$. Found: C: 40.68, H: 4.52, N: 11.27.

General procedure for catalytic transfer hydrogenation. In a $10 \mathrm{~mL}$ one-neck round bottom flask, a mixture of the complex $(0.01 \mathrm{mmol})$, either anisole $(54 \mathrm{mg}, 0.5 \mathrm{mmol})$ or hexamethylbenzene (40 $\mathrm{mg}, 0.25$ mmol) or hexadecane $(226 \mathrm{mg}, 1.0 \mathrm{mmol})$ as internal standard, and $\mathrm{KOH}\left(2 \mathrm{M}\right.$ solution in $\mathrm{H}_{2} \mathrm{O}, 50 \mu \mathrm{L}, 0.1$ $\mathrm{mmol})$ in $i \mathrm{PrOH}(5 \mathrm{~mL})$ was mixed. Then, substrate $(1.0 \mathrm{mmol})$ was added and the reaction mixture heated to reflux in an oil bath $\left(110^{\circ} \mathrm{C}\right)$. Time zero was set when the mixture reached reflux conditions (ca. $\left.30 \mathrm{sec}\right)$. Aliquots (ca. $0.1 \mathrm{~mL}$ ) were taken at set times and dissolved in $\mathrm{CDCl}_{3}$ (for NMR analysis) or diluted in $i \mathrm{PrOH}$ (for GC analysis). Conversions and yields were determined relative to anisole, hexamethylbenzene, or hexadecane as internal standards.

Crystal structure determinations. Suitable single crystals of $\mathbf{L 1}, \mathbf{1}, \mathbf{2 a}-\mathbf{d}$ and $\mathbf{2 f}$ were mounted in air at ambient conditions and measured on an Oxford Diffraction SuperNova area-detector diffractometer ${ }^{65}$ using mirror optics monochromated Mo $K \alpha$ radiation $(\lambda=0.71073 \AA)$ and Al filtered. ${ }^{66}$ Data reduction was performed using the CrysAlisPro ${ }^{65}$ program. The intensities were corrected for Lorentz and polarization effects, and an absorption correction based on the multi-scan method using SCALE3 ABSPACK in CrysAlisPro ${ }^{65}$ was applied. The structure was solved by direct methods using $S H E L X T^{67}$, which revealed 
the positions of all not disordered non-hydrogen atoms. The non-hydrogen atoms were refined anisotropically. All H-atoms were placed in geometrically calculated positions and refined using a riding model where each $\mathrm{H}$-atom was assigned a fixed isotropic displacement parameter with a value equal to 1.2Ueq of its parent atom (1.5Ueq for the methyl groups). Refinement of the structure was carried out on $F^{2}$ using full-matrix least-squares procedures, which minimized the function $\Sigma \mathrm{w}\left(\mathrm{F}_{\mathrm{o}}{ }^{2}-\mathrm{F}_{\mathrm{c}}{ }^{2}\right)^{2}$. The weighting scheme was based on counting statistics and included a factor to downweight the intense reflections. All calculations were performed using the SHELXL-2014/7 $7^{68}$ program. Co-crystallized acetonitrile molecules in the asymmetric unit were found in the crystals of compound $\mathbf{1}$ (two), complex $\mathbf{2 c}$ (three), and complex $\mathbf{2 f}$ (one). The crystal of complex $\mathbf{2 d}$ contained one co-crystallized diethylether molecule in the asymmetric unit. In compounds $\mathbf{1}$ and $\mathbf{2 a - c}$ one methylpyridinium group is conformationally disordered about two orientations. The geometries of the two moieties of disordered methylpyridinium group were constrained to be similar in 2a. Remaining electron density in solvent accessible voids originating from heavily disordered co-crystallized acetonitrile was accounted for with the SQUEEZE function of PLATON ${ }^{69}$ in compounds 1 and $\mathbf{2 b}$. If present, disordered acetonitrile molecules, methylpyridinium groups and $\mathrm{PF}_{6}$ anions were restrained to standard values. Their ADP's were restrained by the SHELXL SIMU and DELU instructions. The ADP's of the second $\mathrm{PF}_{6}$ anion were restrained by the SHELXL RIGU instruction. Further crystallographic details are compiled in Tables S3-S9. Crystallographic data for all structures have been deposited with the Cambridge Crystallographic Data Centre (CCDC) as supplementary publication numbers 1851796 (L1), 1851797 (1), 1851801 (2a), 1851800 (2b), 1851802 (2c), 1851798 (2d), and 1851799 (2f).

Supporting Information Available: Listings of synthetic details, analytical data of the ligands and complexes, NMR data of ligand exchange reactions, time-conversion profiles for transfer hydrogenation and discussion on the reduction of $\alpha, \beta$-unsaturated ketones, NMR spectra of all compounds, and crystallographic details.

\section{Acknowledgements}

We are grateful for generous financial support from the Swiss National Science Foundation (project 2000021_162868, and R'equip projects) as well as the European Research Council (CoG 615653). We thank the group of Chemical Crystallography of the University of Bern (PD Dr. P. Macchi) for the crystallographic analysis. 


\section{Literature}

(1) Peris, E.; Crabtree, R. H. Key Factors in Pincer Ligand Design. Chem. Soc. Rev. 2018, 47, 19591968.

(2) Pincer Compounds: Chemistry and Applications; Morales-Morales, D., Ed.; Elsevier: Amsterdam, NL, 2018.

(3) The Privileged Pincer-Metal Platform: Coordination Chemistry \& Applications; van Koten, G., Gossage, R. A., Eds.; Springer: Berlin, Germany, 2016.

(4) Pincer and Pincer-Type Complexes: Applications in Organic Synthesis and Catalysis; Szabó, K. J., Wendt, O. F., Eds.; Wiley-VCH: Weinheim, Germany, 2014.

(5) Organometallic Pincer Chemistry; van Koten, G., Milstein, D., Eds.; Springer: Berlin, Germany, 2013.

(6) Albrecht, M.; Lindner, M. M. Cleavage of Unreactive Bonds with Pincer Metal Complexes. Dalton. Trans. 2011, 40, 8733-8744.

(7) Selander, N.; Szabó, K. J. Catalysis by Palladium Pincer Complexes. Chem. Rev. 2011, 111, 20482076.

(8) Choi, J.; MacArthur, A. H. R.; Brookhart, M.; Goldman, A. S. Dehydrogenation and Related Reactions Catalyzed by Iridium Pincer Complexes. Chem. Rev. 2011, 111, 1761-1779.

(9) Van Der Boom, M. E.; Milstein, D. Cyclometalated Phosphine-Based Pincer Complexes: Mechanistic Insight in Catalysis, Coordination, and Bond Activation. Chem. Rev. 2003, 103, 17591792.

(10) Albrecht, M.; Van Koten, G. Platinum Group Organometallics Based on "Pincer" Complexes: Sensors, Switches, and Catalysts. Angew. Chem. Int. Ed. 2001, 40, 3750-3781.

(11) Moulton, C. J.; Shaw, B. L. Transition Metal-Carbon Bonds. Part XLII. Complexes of Nickel, Palladium, Platinum, Rhodium and Iridium with the Tridentate Ligand 2,6-Bis[(Di-tButylphosphino)Methyl]Phenyl. J. Chem. Soc., Dalton. Trans. 1976, 0, 1020-1024.

(12) van Koten, G.; Timmer, K.; Noltes, J. G.; Spek, A. L. A Novel Type of Pt-C Interaction and a Model for the Final Stage in Reductive Elimination Processes Involving C-C Coupling at Pt; Synthesis and Molecular Geometry of [1,N,N'- $\eta-2,6-B i s\{($ Dimethylamino)Methyl $\}$-Toluene]Iodoplatinum(II) Tetrafluoroborate. J.Chem.Soc., Chem. Comm. 1978, 0, 250-252. 
van Koten, G.; Jastrzebski, J. T. B. H.; Noltes, J. G.; Spek, A. L.; Schoone, J. C. Triorganotin Cations Stabilized by Intramolecular $\mathrm{SnN}$ Coordination; Synthesis and Characterization of $\left\{\mathrm{C}, \mathrm{N}, \mathrm{N}^{\prime}-2,6-\mathrm{Bis}[(\right.$ Dimethylamino$)$ Methyl $]$ Phenyl $\}$ diorganotin Bromides. J. Organomet. Chem. 1978, 148, 233-245.

(14) Abbenhuis, H. C. L.; Nantko, F.; Haarman, H. F.; Grove, D. M.; Horn, E.; Kooijman, H.; Spek, A. L.; van Koten, G. Effect of Intramolecular Coordination on Tantalum-Alkylidene-Centered Reactions: Synthesis and Structure of a Tantalum-Olefin Adduct and a Tantalum-Zinc-Alkylidene Complex. Angew. Chem. Int. Ed. 1991, 30, 996-998.

Abbenhuis, H. C. L.; Feiken, N.; Grove, D. M.; Jastrzebski, J. T. B. H.; Kooijman, H.; van der Sluis, P.; Smeets, W. J. J.; Spek, A. L.; van Koten, G. Use of an Aryldiamine Pincer Ligand in the Study of Tantalum Alkylidene-Centered Reactivity: Tantalum-Mediated Alkene Synthesis via Reductive Rearrangements and Wittig-Type Reactions. J. Am. Chem. Soc. 1992, 114, 9773-9781.

(16) van Beek, J. A. M.; van Koten, G.; Smeets, W. J. J.; Spek, A. L. Model for the Initial Stage in the Oxidative Addition of $\mathrm{I}_{2}$ to Organoplatinum(II) Compounds. X-ray Structure of Square-Pyramidal $\left[\mathrm{Pt}^{\mathrm{II}} \mathrm{I}\left\{\mathrm{C}_{6} \mathrm{H}_{3}\left(\mathrm{CH}_{2} \mathrm{NMe}_{2}\right)_{2}-o, o^{\prime}\right\}\left(\eta^{1}-\mathrm{I}_{2}\right)\right]$ Containing a Linear Pt-I-I Arrangement. J. Am. Chem. Soc. 1986, 108, 5010-5011.

(17) Vigalok, A.; Milstein, D. Metal-Stabilized Quinone and Thioquinone Methides. J. Am. Chem. Soc. 1997, 119, 7873-7874.

(18) Vigalok, A.; Shimon, L. J. W.; Milstein, D. Methylene Arenium Cations via Quinone Methides and Xylylenes Stabilized by Metal Complexation. J. Am. Chem. Soc. 1998, 120, 477-483.

Albrecht, M.; Gossage, R. A.; Spek, A. L.; van Koten, G. Metal-Mediated C-C Bond Making and Breaking : First Direct Evidence for a Reversible Migration of a Benzyl Group along a MetalCarbon Bond. J. Am. Chem. Soc. 1999, 121, 11898-11899.

(20) Terheijden, J.; van Koten, G.; Vinke, I. C.; Spek, A. L. 1,2-Methyl Shift between Pt and the Coordinated Aryl Group in the Reaction of Methyl Iodide with 2,6Bis[(Dimethylamino)Methyl]Phenyl-N,N',C Complexes of Platinum(II). X-Ray Crystal Structure of the Arenonium-Platinum Compound [Pt(o-Tolyl) $\left.\left(\mathrm{MeC}_{6} \mathrm{H}_{3}\left(\mathrm{CH}_{2} \mathrm{NMe}_{2}\right)_{2}-\mathrm{o}, o^{\prime}\right)\right]$ I. J. Am. Chem. Soc. 1985, 107, 2891-2898.

(21) Vigalok, A.; Rybtchinski, B.; Shimon, L. J. W.; Ben-David, Y.; Milstein, D. Metal-Stabilized Methylene Arenium and $\sigma$-Arenium Compounds: Synthesis, Structure, Reactivity, Charge Distribution, and Interconversion. Organometallics 1999, 18, 895-905. 
(22) Gunanathan, C.; Milstein, D. Bond Activation and Catalysis by Ruthenium Pincer Complexes. Chem. Rev. 2014, 114, 12024-12087.

(23) Poverenov, E.; Milstein, D. Noninnocent Behavior of PCP and PCN Pincer Ligands of Late Metal Complexes. Top. Organomet. Chem. 2013, 40, 21-48.

Zhang, J.; Leitus, G.; Ben-David, Y.; Milstein, D. Facile Conversion of Alcohols into Esters and Dihydrogen Catalyzed by New Ruthenium Complexes. J. Am. Chem. Soc. 2005, 127, 10840-10841.

(25) Gunanathan, C.; Milstein, D. Metal-Ligand Cooperation by Aromatization-Dearomatization: A New Paradigm in Bond Activation and "Green" Catalysis. Acc. Chem. Res. 2011, 44, 588-602.

(26) Ben-Ari, E.; Leitus, G.; Shimon, L. J. W.; Milstein, D. Metal-Ligand Cooperation in C-H and H2 Activation by an Electron-Rich PNP Ir(I) System: Facile Ligand Dearomatization-Aromatization as Key Steps. J. Am. Chem. Soc. 2006, 128, 15390-15391.

(27) Khusnutdinova, J. R.; Milstein, D. Metal-Ligand Cooperation. Angew. Chem. Int. Ed. 2015, 54, 12236-12273.

(28) Khusnutdinova, J. R.; Garg, J. A.; Milstein, D. Combining Low-Pressure $\mathrm{CO}_{2}$ Capture and Hydrogenation to Form Methanol. ACS Catal. 2015, 5, 2416-2422.

(29) Kohl, S. W.; Weiner, L.; Schwartsburd, L.; Konstantinovski, L.; Shimon, L. J. W.; Ben-David, Y.; Iron, M. A.; Milstein, D. Consecutive Thermal $\mathrm{H}_{2}$ and Light-Induced $\mathrm{O}_{2}$ Evolution from Water Promoted by a Metal Complex. Science 2009, 324, 74-77.

(30) Gunanathan, C.; Ben-David, Y.; Milstein, D. Direct Synthesis of Amides from Alcohols and Amines with Liberation of $\mathrm{H}_{2}$. Science 2007, 317, 790-792.

(31) Shvo, Y.; Czarkie, D.; Rahamim, Y.; Chodosh, D. F. A New Group of Ruthenium Complexes: Structure and Catalysis. J. Am. Chem. Soc. 1986, 108, 7400-7402.

(32) Noyori, R.; Ohkuma, T.; Kitamura, M.; Takaya, H.; Sayo, N.; Kumobayashi, H.; Akutagawa, S. Asymmetric Hydrogenation of $\beta$-Keto Carboxylic Esters. A Practical, Purely Chemical Access to $\beta$-Hydroxy Esters in High Enantiomeric Purity. J. Am. Chem. Soc. 1987, 109, 5856-5858.

Schneck, F.; Finger, M.; Tromp, M.; Schneider, S. Chemical Non-Innocence of an Aliphatic PNP Pincer Ligand. Chem. Eur. J. 2017, 23, 33-37.

(34) Rösler, S.; Obenauf, J.; Kempe, R. A Highly Active and Easily Accessible Cobalt Catalyst for Selective Hydrogenation of C=O Bonds. J. Am. Chem. Soc. 2015, 137, 7998-8001. 
(35) Thatcher, R. J.; Johnson, D. G.; Slattery, J. M.; Douthwaite, R. E. Charged Behaviour from Neutral Ligands: Synthesis and Properties of N-Heterocyclic Pseudo-Amides. Chem. Eur. J. 2012, 18, 4329-4336.

(36) Shi, Q.; Thatcher, R. J.; Slattery, J.; Sauari, P. S.; Whitwood, A. C.; McGowan, P. C.; Douthwaite, R. E. Synthesis, Coordination Chemistry and Bonding of Strong N-Donor Ligands Incorporating the 1H-Pyridin-(2E)-Ylidene (PYE) Motif. Chem. Eur. J. 2009, 15, 11346-11360.

(37) Brzezinski, B.; Zundel, G. An Intramolecular Charge Relay System via Easily Polarizable Hydrogen Bonds in the $N$-(4-Methyl-2-Pyridyl)Amide of 6-Methylpicolinic Acid N-Oxide. J. Phys. Chem. 1979, 83, 1787-1789.

(38) Chien, C. H.; Leung, M. K.; Su, J. K.; Li, G. H.; Liu, Y. H.; Wang, Y. Substituent Effects on Pyrid2-yl Ureas toward Intramolecular Hydrogen Bonding and Cytosine Complexation. J. Org. Chem. 2004, 69, 1866-1871.

(39) Rais, D.; Gould, I. R.; Vilar, R.; White, A. J. P.; Williams, D. J. Structural and Theoretical Studies of New Ruthenium-Amidato Complexes with Phenanthroline Ligands Containing H-Bonding Groups. Eur. J. Inorg. Chem. 2004, 1865-1872.

(40) Doster, M. E.; Johnson, S. A. Selective C-F Bond Activation of Tetrafluorobenzenes by Nickel(0) with a Nitrogen Donor Analogous to N-Heterocyclic Carbenes. Angew. Chem. Int. Ed. 2009, 48, $2185-2187$.

(41) Boyd, P. D. W.; Wright, L. J.; Zafar, M. N. Extending the Range of Neutral N-Donor Ligands Available for Metal Catalysts: $N$-[1-Alkylpyridin-4(1H)-Ylidene]Amides in Palladium-Catalyzed Cross-Coupling Reactions. Inorg. Chem. 2011, 50, 10522-10524.

(42) Doster, M. E.; Hatnean, J. A.; Jeftic, T.; Modi, S.; Johnson, S. A. Catalytic C-H Bond Stannylation: A New Regioselective Pathway to C-Sn Bonds via C-H Bond Functionalization. J. Am. Chem. Soc. 2010, 132, 11923-11925.

(43) Doster, M. E.; Johnson, S. A. Carbon-Hydrogen Bond Stannylation and Alkylation Catalyzed by Nitrogen-Donor-Supported Nickel Complexes: Intermediates with $\mathrm{Ni}-\mathrm{Sn}$ Bonds and Catalytic Carbostannylation of Ethylene with Organostannanes. Organometallics 2013, 32, 4174-4184.

(44) Leigh, V.; Carleton, D. J.; Olguin, J.; Mueller-Bunz, H.; Wright, L. J.; Albrecht, M. SolventDependent Switch of Ligand Donor Ability and Catalytic Activity of Ruthenium(II) Complexes Containing Pyridinylidene Amide (PYA) N-Heterocyclic Carbene Hybrid Ligands. Inorg. Chem. 2014, 53, 8054-8060. 
Navarro, M.; Li, M.; Müller-Bunz, H.; Bernhard, S.; Albrecht, M. Donor-Flexible Nitrogen Ligands for Efficient Iridium-Catalyzed Water Oxidation Catalysis. Chem. Eur. J. 2016, 22, 6740-6745.

(46) Navarro, M.; Smith, C. A.; Albrecht, M. Enhanced Catalytic Activity of Iridium(III) Complexes by Facile Modification of C,N-Bidentate Chelating Pyridylideneamide Ligands. Inorg. Chem. 2017, $56,11688-11701$.

(47) Navarro, M.; Smith, C. A.; Li, M.; Bernhard, S.; Albrecht, M. Optimization of Synthetically Versatile Pyridylidene Amide Ligands for Efficient Iridium-Catalyzed Water Oxidation. Chem. Eur. J. 2018, 24, 6386-6398.

(48) Navarro, M.; Li, M.; Bernhard, S.; Albrecht, M. A Mesoionic Nitrogen-Donor Ligand: Structure, Iridium Coordination, and Catalytic Effects. Dalton Trans. 2017, 47, 659-662.

(49) Mesoionic compounds are defined by IUPAC as "dipolar five- (possibly six-) membered heterocyclic compounds in which both the negative and the positive charge are delocalized, for which a totally covalent structure cannot be written, and which cannot be represented satisfactorily by any one polar structure. The formal positive charge is associated with the ring atoms, and the formal negative charge is associated with ring atoms or an exocyclic nitrogen or chalcogen atom." IUPAC. Compendium of Chemical Terminology, 2nd edn. Gold Book Compiled by A. D. McNaught and A. Wilkinson, Blackwell Scientific Publications, Oxford, 1997. XML on-line corrected version: http://goldbook.iupac.org (2006) created by M. Nic, J. Jirat, and B. Kosata updates compiled by A. Jenkins. ISBN 0-9678550-9-8.

(50) Schuster, O.; Yang, L.; Raubenheimer, H. G.; Albrecht, M. Beyond Conventional N-Heterocyclic Carbenes: Abnormal, Remote, and Other Classes of NHC Ligands with Reduced Heteroatom Stabilization. Chem. Rev. 2009, 109, 3445-3478.

(51) Crabtree, R. H. Abnormal, Mesoionic and Remote N-Heterocyclic Carbene Complexes. Coord. Chem. Rev. 2013, 257, 755-766.

Donnelly, K. F.; Petronilho, A.; Albrecht, M. Application of 1,2,3-Triazolylidenes as Versatile NHC-Type Ligands: Synthesis, Properties, and Application in Catalysis and Beyond. Chem. Commun. 2013, 49, 1145-1159.

(53) Dorazco-González, A.; Höpfl, H.; Medrano, F.; Yatsimirsky, A. K. Recognition of Anions and Neutral Guests by Dicationic Pyridine-2,6-Dicarboxamide Receptors. J. Org. Chem. 2010, 75, $2259-2273$. 
(54) Wang, D.; Astruc, D. The Golden Age of Transfer Hydrogenation. Chem. Rev. 2015, 115, 66216686.

(55) Coe, B. J.; Glenwright, S. J. Trans-Effects in Octahedral Transition Metal Complexes. Coord. Chem. Rev. 2000, 203, 5-80.

Complexes $\mathbf{2 a}$, 2e, and $\mathbf{2 f}$ show a second reversible redox process at higher potentials which was assigned to a $\mathrm{Ru}^{\mathrm{III} / \mathrm{V} \mathrm{V}}$ transition at $1.65 \mathrm{~V}$ for $\mathbf{2 e}$, and $1.84 \mathrm{~V}$ for $\mathbf{2 f}$ (Fig. S6, S7). No additional redox process was observed for complexes $\mathbf{2 b}-\mathbf{d}$ up to $2.1 \mathrm{~V}$.

(57) Clapham, S. E.; Hadzovic, A.; Morris, R. H. Mechanisms of the $\mathrm{H}_{2}$-Hydrogenation and Transfer Hydrogenation of Polar Bonds Catalyzed by Ruthenium Hydride Complexes. Coord. Chem. Rev. 2004, 248, 2201-2237.

(58) Moore, C. M.; Szymczak, N. K. 6,6'-Dihydroxy Terpyridine: A Proton-Responsive Bifunctional Ligand and Its Application in Catalytic Transfer Hydrogenation of Ketones. Chem. Commun. 2013, $49,400-402$.

(60) Meyer, N.; Lough, A. J.; Morris, R. H. Iron(II) Complexes for the Efficient Catalytic Asymmetric Transfer Hydrogenation of Ketones. Chem. Eur. J. 2009, 15, 5605-5610.

(61) Noyori, R.; Ohkuma, T. Asymmetric Catalysis by Architectural and Functional Molecular Engineering: Practical Chemo- and Stereoselective Hydrogenation of Ketones. Angew. Chem. Int. Ed. 2001, 40, 40-73.

(62) Liu, T.; Zeng, Y.; Zhang, H.; Wei, T.; Wu, X.; Li, N. Facile Pd-Catalyzed Chemoselective Transfer Hydrogenation of Olefins Using Formic Acid in Water. Tetrahedron Lett. 2016, 57, 4845-4849.

(63) Baan, Z.; Finta, Z.; Keglevich, G.; Hermecz, I. Unexpected Chemoselectivity in the RhodiumCatalyzed Transfer Hydrogenation of $\alpha, \beta$-Unsaturated Ketones in Ionic Liquids. Green Chem. 2009, 11, 1937-1940.

(64) Connelly, N. G.; Geiger, W. E. Chemical Redox Agents for Organometallic Chemistry. Chem. Rev. 1996, 96, 877-910.

(65) CrysAlisPro, Version 1.; Oxford Diffraction Ltd., Ed.; Yarnton, Oxfordshire, U.K., 2010. 
(66) Macchi, P.; Bürgi, H.-B.; Chimpri, A. S.; Hauser, J.; Gál, Z. Low-Energy Contamination of Mo Microsource X-Ray Radiation: Analysis and Solution of the Problem. J. Appl. Cryst. 2011, 44, $763-$ 771.

(67) Sheldrick, G. M. SHELXT - Integrated Space-Group and Crystal-Structure Determination. Acta Crystallogr. Sect. A 2015, 71, 3-8.

(68) Sheldrick, G. M. Crystal Structure Refinement with SHELXL. Acta Crystallogr. Sect. C 2015, 71, 3-8.

(69) Spek, A. L. PLATON SQUEEZE: A Tool for the Calculation of the Disordered Solvent Contribution to the Calculated Structure Factors. Acta Crystallogr. Sect. C 2015, 71, 9-18. 


\section{Table of Contents entry:}
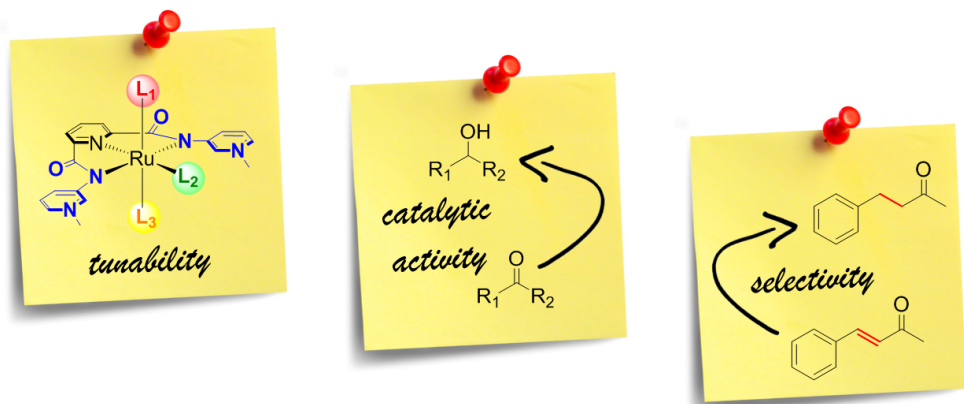

Pincer ligands containing pyridylidene amide donor groups impart unique electronic properties to the ruthenium center, which can be modulated by the type of pincer ligand and the ancillary ligands. This approach produces transfer hydrogenation catalysts with rationally tunable catalytic activity, and with reactivity that can be tailored to convert also challenging substrates. 